\title{
Article \\ Mammalian and Invertebrate Models as Complementary Tools for Gaining Mechanistic Insight on Muscle Responses to Spaceflight
}

\author{
Thomas Cahill ${ }^{1}$, Henry Cope ${ }^{2}\left(\mathbb{D}\right.$, Joseph J. Bass ${ }^{3}{ }^{\oplus}$, Eliah G. Overbey ${ }^{4}$, Rachel Gilbert ${ }^{5,6}$, \\ Willian Abraham da Silveira ${ }^{1,7} \mathbb{1}^{\circ}$, Amber M. Paul ${ }^{5,8,9}$, Tejaswini Mishra ${ }^{10}$, Raúl Herranz ${ }^{11}$, Sigrid S. Reinsch ${ }^{5} \mathbb{D}^{\mathbb{D}}$, \\ Sylvain V. Costes ${ }^{5}$, Gary Hardiman ${ }^{1,12} \oplus$, Nathaniel J. Szewczyk ${ }^{3,13}{ }^{-}$and Candice G. T. Tahimic ${ }^{5,14, *}$
}

check for updates

Citation: Cahill, T.; Cope, H.; Bass, J.J.; Overbey, E.G.; Gilbert, R.; da Silveira, W.A.; Paul, A.M.; Mishra, T.; Herranz, R.; Reinsch, S.S.; et al.

Mammalian and Invertebrate Models as Complementary Tools for Gaining Mechanistic Insight on Muscle Responses to Spaceflight. Int. J. Mol. Sci. 2021, 22, 9470. https://doi.org/ 10.3390/ijms22179470

Academic Editors:

Melpo Christofidou-Solomidou and Thomas J. Goodwin

Received: 30 July 2021

Accepted: 23 August 2021

Published: 31 August 2021

Publisher's Note: MDPI stays neutral with regard to jurisdictional claims in published maps and institutional affiliations.

Copyright: (c) 2021 by the authors. Licensee MDPI, Basel, Switzerland. This article is an open access article distributed under the terms and conditions of the Creative Commons Attribution (CC BY) license (https:// creativecommons.org/licenses/by/ $4.0 /)$.
1 School of Biological Sciences \& Institute for Global Food Security, Queens University Belfast, Belfast BT9 5DL, UK; tcahill01@qub.ac.uk (T.C.); willian.dasilveira@staffs.ac.uk (W.A.d.S.); g.hardiman@qub.ac.uk (G.H.)

2 Nottingham Biomedical Research Centre (BRC), School of Computer Science, University of Nottingham, Nottingham NG7 2QL, UK; henry.cope@nottingham.ac.uk

3 MRC-Versus Arthritis Centre for Musculoskeletal Ageing Research and National Institute for Health Research (NIHR), Nottingham Biomedical Research Centre (BRC), University of Nottingham, Nottingham NG7 2QL, UK; joseph.bass2@nottingham.ac.uk (J.J.B.); szewczyk@ohio.edu (N.J.S.)

4 Department of Genome Sciences, University of Washington, Seattle, WA 98195, USA; eliah@uw.edu

5 NASA Ames Research Center, Space Biosciences Division, Moffett Field, CA 94035, USA; rachelrgilbert11@gmail.com (R.G.); amber.paul@erau.edu (A.M.P.); sigrid.reinsch@nasa.gov (S.S.R.); sylvain.v.costes@nasa.gov (S.V.C.)

6 Universities Space Research Association, Columbia, MD 21046, USA

7 Department of Biological Sciences, School of Life Sciences and Education, Staffordshire University, Stoke-on-Trent ST4 2DF, UK

8 Department of Human Factors and Behavioral Neurobiology, Embry-Riddle Aeronautical University, Daytona Beach, FL 32114, USA

9 Blue Marble Space Institute of Science, Seattle, WA 98104, USA

10 Department of Genetics, Stanford University School of Medicine, Palo Alto, CA 94305, USA; tejaswini.mishra@stanford.edu

11 Centro de Investigaciones Biológicas Margarita Salas-CSIC, Ramiro de Maeztu 9, 28040 Madrid, Spain; rherranz@cib.csic.es

12 Department of Medicine, Medical University of South Carolina, Charleston, SC 29425, USA

13 Department of Biomedical Sciences, Heritage College of Osteopathic Medicine, Ohio University, Athens, OH 45701, USA

14 Department of Biology, University of North Florida, Jacksonville, FL 32224, USA

* Correspondence: c.tahimic@unf.edu

\begin{abstract}
Bioinformatics approaches have proven useful in understanding biological responses to spaceflight. Spaceflight experiments remain resource intensive and rare. One outstanding issue is how to maximize scientific output from a limited number of omics datasets from traditional animal models including nematodes, fruitfly, and rodents. The utility of omics data from invertebrate models in anticipating mammalian responses to spaceflight has not been fully explored. Hence, we performed comparative analyses of transcriptomes of soleus and extensor digitorum longus (EDL) in mice that underwent 37 days of spaceflight. Results indicate shared stress responses and altered circadian rhythm. EDL showed more robust growth signals and Pde2a downregulation, possibly underlying its resistance to atrophy versus soleus. Spaceflight and hindlimb unloading mice shared differential regulation of proliferation, circadian, and neuronal signaling. Shared gene regulation in muscles of humans on bedrest and space flown rodents suggest targets for mitigating muscle atrophy in space and on Earth. Spaceflight responses of C. elegans were more similar to EDL. Discrete life stages of D. melanogaster have distinct utility in anticipating EDL and soleus responses. In summary, spaceflight leads to shared and discrete molecular responses between muscle types and invertebrate models may augment mechanistic knowledge gained from rodent spaceflight and ground-based studies.
\end{abstract}


Keywords: spaceflight; muscle; transcriptomics; bedrest; hindlimb unloading; microgravity; animal models; cross-species comparison

\section{Introduction}

Exposure to the unique set of spaceflight environmental conditions, including microgravity, cosmic radiation, isolation, and confinement, has been shown to induce significant physiological changes in all studied species to date [1-3]. These physiological responses, such as skeletal muscle atrophy, can negatively impact the health of astronauts and may also compromise mission success if left unabated [4]. The precise molecular mechanisms underlying physiological deconditioning in spaceflight have yet to be fully described, and advancement of this mechanistic understanding is essential for the development of molecularly rationalized countermeasures [5]. Such countermeasures can help maintain astronaut health during future spaceflight missions, including long duration voyages to Mars in which current countermeasures are likely to prove insufficient [6].

Studies leveraging data from omics disciplines, including transcriptomics, allow for a detailed study of the complex interactions between the molecular landscape of biological systems and spaceflight environmental conditions. Despite the scientific potential of omics datasets captured in spaceflight, only a relatively small number have been collected, mainly due to the resource-intensive nature of spaceflight experiments. NASA GeneLab was established to maximize the use of the limited number of spaceflight omics datasets. The datasets made publicly available via the GeneLab repository represent a variety of omics data types and a range of model organisms, including microbes, plants, cell cultures, vertebrates, and invertebrates [7,8]. Additionally, datasets from ground-based studies that are relevant to the spaceflight environment can be accessed via public repositories, including GeneLab and NCBI Gene Expression Omnibus (GEO) [9]. Although physiological and other functional data is required to establish clear relationships between omics changes and physiological changes, independent analysis of omics datasets is still useful for hypothesis generation, which can be used to inform future research directions. There remain numerous opportunities to use publicly available omics datasets to elucidate knowledge gaps in the field of space biology.

One such knowledge gap that currently requires further investigation is that of shared and discrete transcriptomic responses across biological tissue types, such as different muscles. Addressing this knowledge gap can prove useful for designing countermeasures that can target multiple tissues, or for providing evidence for the need to employ multiple countermeasures to provide comprehensive protection to a variety of tissues. Aside from its role in locomotion and posture, skeletal muscle plays other vital roles in whole-body health. Skeletal muscle physically shields organs and helps maintain temperature homeostasis. Additionally, as the body's largest store of amino acids, skeletal muscle engages in crosstalk with other organs, to synthesize organ-specific proteins [10]. When the body is threatened by starvation or disease, skeletal muscle is broken down to provide other organs with energy [11].

To date, antigravity muscles in the limbs have been the main focus for studying the skeletal muscle response to spaceflight. These muscles are key to maintaining posture under 1G conditions, and are thus highly susceptible to atrophy when unloaded [12]. Certain antigravity muscles in the lower limb, such as the soleus and gastrocnemius, are also important for circulation, as upon contraction they pump venous blood back to the heart, preventing pooling and stagnation [13].

Alongside reduced muscle mass, strength, and endurance, it has been found that the mechanical unloading associated with microgravity induces a shift from type I slow twitch fibers to type II fast twitch fibers [14,15]. Previous spaceflight and ground studies in rodents and humans have also observed that antigravity muscles consisting of mainly type I (slowtwitch) fibers, which are designed for slow and sustained contraction, such as the soleus 
tend to be more susceptible to atrophy compared to antigravity muscles with more type II (fast-twitch) fibers [16]. Recently, Choi and colleagues reported findings from NASA's Rodent Research-1 (RR-1) mission, in which mice were flown onboard the International Space Station (ISS) and exposed to microgravity for 37 days. They found that the weight of the soleus in space flown mice was reduced by $\sim 19 \%$ compared to ground control mice [17]. In addition, they reported that the gastrocnemius, tibialis anterior (TA), extensor digitorum longus (EDL), and quadriceps did not show significant atrophy compared to ground control mice [17]. While significant atrophy of the soleus is consistent with findings from similar studies, the finding of non-significant atrophy in the gastrocnemius is contrary to previous space flown mouse studies [18-20].

Similarly, previous transcriptomic analyses of RR-1 data have reported that the soleus showed the greatest number of significant differentially expressed genes (DEGs) [21,22] compared to other muscle tissues. However, all muscle tissues did show significant gene expression changes, and hierarchical clustering of these changes indicated that the muscle tissues can be divided into two distinct groups. Group 1 consisted of plantar flexor muscles, soleus, and gastrocnemius, while group 2 consisted of dorsiflexors EDL and TA and knee extensors, quadriceps. In addition, microgravity responsive changes in immune-related pathway regulation appeared to be more prevalent in group 1 muscles compared to group 2 [21]. A different analysis of RR-1 data highlighted that changes in the expression of clock genes were fairly uniform across the muscle tissues, and yet distinct compared to other tissues such as the liver [22]. Taken together, these findings demonstrate that while certain muscles may not undergo significant atrophy in spaceflight, they still undergo molecular changes that may require intervention. Additionally, these findings support the hypothesis that in certain cases, the response to spaceflight is not identical between muscle tissues, due to their distinct morphologies and locomotive functions [16]. Further investigation is required to establish precise differences and similarities between the molecular responses of different muscle tissues. Hence in this study, we compared transcriptomic data from the fast-twitch enriched EDL, and the representative slow-twitch muscle soleus [23], collected during the RR-1 mission. We made use of two analysis approaches, Gene Set Enrichment Analysis (GSEA) and overrepresentation analysis (ORA) to determine the impact of the analysis approach on outcomes and to better anticipate the array of biological responses to spaceflight. Subsequently, to better understand the analogous nature of ground-based studies, transcriptomic data from the RR-1 quadriceps was compared to the vastus lateralis from a human bed rest study [24], and transcriptomic data from the gastrocnemius from a different space flown mouse study was compared to matching HU samples from that same study [25].

In addition to rodents, invertebrates, including C. elegans and D. melanogaster, have been established as important model organisms for understanding biological responses to the space environment [26]. While it is possible to isolate muscles in ground laboratories via dissection when the sample size of fresh animals is sufficient [27], whole organism or composite structures such as the head are typically extracted for analysis in spaceflight experiments due to logistical challenges of dissecting samples in orbit. However, insights related to muscle can still be uncovered. For example, reproducible downregulation of muscle-related genes has been observed across the "International C. elegans Experiment FIRST" (ICE-FIRST) and "C. elegans RNA Interference in Space Experiment" (CERISE) microarray experiments $[28,29]$. Leandro and colleagues performed a comparative analysis of space flown C. elegans from the ICE-FIRST experiment and space flown D. melanogaster from the GENE experiment $[3,30]$. Three analysis approaches were tested on the small subset of orthologous genes between the two organisms. Only six genes were found to have a common transcriptomic response in both experiments, with these genes all downregulated and associated with metabolic and neuromuscular signaling [3,31].

Terrestrial studies have set a strong precedent for using invertebrate models to develop tools $[13,32,33]$ and study conserved pathways in mammalian biological processes such as aging [34-38]. However, the utility of omics data from space flown invertebrate 
studies, in anticipating aspects of mammalian responses to spaceflight, has yet to be fully investigated. With large, low cost cohorts of genetic mutants, interventional invertebrate studies are useful for establishing correlational relationships between molecular pathways and spaceflight phenotypes, with functional measures needed for causation [29]. We reason that if certain mechanisms are shared between mammals and invertebrate models, invertebrate datasets can potentially augment the limited quantity of vertebrate spaceflight omics datasets. This in turn may prove useful in anticipating mammalian responses to spaceflight. To test these concepts, we compared the abovementioned RR-1 EDL and soleus muscle datasets with transcriptomic datasets of $C$. elegans and D. melanogaster that were flown in the ICE-FIRST experiment and STS-121 mission, respectively. We found that spaceflight results in discrete transcriptomic signatures between representative slow and fast twitch muscles (soleus and EDL respectively), consistent with their opposing roles in flexion and differential sensitivities to unloading. In addition, transcriptomic analysis revealed that invertebrate models share select aspects of mammalian responses to spaceflight. The life stage of invertebrate models appears to impact the degree by which they recapitulate the responses of mammalian tissues to spaceflight.

\section{Results}

\subsection{Datasets Used in This Study}

Table 1 shows the transcriptomic datasets used in this study. These datasets included RNA-seq and microarray datasets. Model organisms represented are mouse, fruitfly, and nematode. A bedrest study was also selected for analysis (Refer to Methods section for further details on criteria).

Table 1. Datasets used in the study, including the organism's name, duration of spaceflight or unloading, assay type, sex, strain, tissue, age, and sample size. Refer to GeneLab and GEO databases for further details. GC: ground control, FLT: spaceflight, VC: vivarium control, HU: hindlimb unloading, Gastroc: gastrocnemius, Quad: quadriceps, VL: vastus lateralis, F: female, M: male, Mx: mixed; H: hermaphrodite. Tg: Gal4-UAS transgenic line expressing two copies of eGFP from the hemolectin promoter. N: number of individuals, rep: replicate of pooled samples run for transcriptomic analysis. Refer to $[24,25,37-43]$ for links to GeneLab processed data and versions used in this study.

\begin{tabular}{|c|c|c|c|c|c|c|c|c|c|}
\hline Dataset & Organism & Duration & Vehicle & Assay & Sex & Strain & Tissue & Age/Stage & Sample Size \\
\hline $\begin{array}{c}\text { GLDS- } \\
104\end{array}$ & $\begin{array}{c}\text { M. } \\
\text { musculus }\end{array}$ & $37 \mathrm{~d}$ & ISS & RNAseq & $\mathrm{F}$ & C57BL/6J & Soleus & 16 wks & $\begin{array}{c}\mathrm{N}=6(\mathrm{GC}) ; \mathrm{N}=6 \\
(\mathrm{FLT})\end{array}$ \\
\hline GLDS-99 & $\begin{array}{c}\text { M. } \\
\text { musculus }\end{array}$ & $37 \mathrm{~d}$ & ISS & RNAseq & $\mathrm{F}$ & C57BL/6J & EDL & 16 wks & $\begin{array}{c}\mathrm{N}=6(\mathrm{GC}) ; \mathrm{N}=6 \\
(\mathrm{FLT})\end{array}$ \\
\hline GLDS-21 & $\begin{array}{c}\text { M. } \\
\text { musculus }\end{array}$ & $\begin{array}{l}11 \mathrm{~d}, \\
19 \mathrm{~h}\end{array}$ & STS-108 & Microarray & $\mathrm{F}$ & C57BL/6J & Gastroc & 9 wks & $\begin{array}{c}\mathrm{N}=4(\mathrm{GC}) ; \mathrm{N}=4 \\
(\mathrm{FLT})\end{array}$ \\
\hline GLDS-21 & $\begin{array}{c}\text { M. } \\
\text { musculus }\end{array}$ & $12 \mathrm{~d}$ & $\begin{array}{l}\mathrm{N} / \mathrm{A} \\
(\mathrm{HU})\end{array}$ & Microarray & $\mathrm{F}$ & C57BL/6J & Gastroc & 9 wks & $\begin{array}{c}\mathrm{N}=5(\mathrm{VC}) ; \mathrm{N}=5 \\
(\mathrm{HU})\end{array}$ \\
\hline $\begin{array}{l}\text { GLDS- } \\
103\end{array}$ & $\begin{array}{c}\text { M. } \\
\text { musculus }\end{array}$ & $37 \mathrm{~d}$ & ISS & RNAseq & $\mathrm{F}$ & C57BL/6J & Quad & $16 \mathrm{wks}$ & $\begin{array}{c}\mathrm{N}=6(\mathrm{GC}) ; \mathrm{N}=6 \\
(\mathrm{FLT})\end{array}$ \\
\hline $\begin{array}{c}\text { GLDS- } \\
\text { 370/GEO } \\
\text { GSE24215 }\end{array}$ & H. sapiens & $10 \mathrm{~d}$ & $\begin{array}{c}\mathrm{N} / \mathrm{A} \\
\text { (Bedrest) }\end{array}$ & Microarray & $\mathrm{M}$ & $\mathrm{N} / \mathrm{A}$ & VL & $\begin{array}{c}24-27 \\
\text { yrs }\end{array}$ & $\begin{array}{c}\mathrm{N}=10 \\
\text { (Longitudinal) }\end{array}$ \\
\hline GLDS-3 & $\begin{array}{l}D . \\
\text { melanogaster }\end{array}$ & $\begin{array}{l}12 \mathrm{~d} \\
18.5 \mathrm{~h}\end{array}$ & STS-121 & Microarray & $\mathrm{Mx}$ & $\mathrm{Tg}$ & $\begin{array}{l}\text { Whole } \\
\text { organ- } \\
\text { ism }\end{array}$ & $\begin{array}{l}\text { 3rd } \\
\text { instar } \\
\text { larvae }\end{array}$ & $\begin{array}{l}\mathrm{N}=50 / \text { rep } \times 6(\mathrm{GC}) \\
\mathrm{N}=50 / \text { rep } \times 6(\mathrm{FLT})\end{array}$ \\
\hline GLDS-3 & $\begin{array}{c}D . \\
\text { melanogaster }\end{array}$ & $\begin{array}{l}12 \mathrm{~d} \\
18.5 \mathrm{~h}\end{array}$ & STS-121 & Microarray & $\mathrm{F}$ & $\mathrm{Tg}$ & $\begin{array}{l}\text { Whole } \\
\text { organ- } \\
\text { ism }\end{array}$ & Adults & $\begin{array}{l}\mathrm{N}=20 / \text { rep } \times 3(\mathrm{GC}) \\
\mathrm{N}=20 / \text { rep } \times 3(\mathrm{FLT})\end{array}$ \\
\hline $\begin{array}{l}\text { GLDS- } \\
113\end{array}$ & C. elegans & $10 \mathrm{~d}$ & ISS & Microarray & $\mathrm{H}$ & N2 & $\begin{array}{l}\text { Whole } \\
\text { organ- } \\
\text { ism }\end{array}$ & $\begin{array}{l}\text { Mixed } \\
\text { stage }\end{array}$ & $\begin{aligned} & \mathrm{N} \approx 10000 / \mathrm{rep} \times 3 \\
&(\mathrm{GC}) ; \mathrm{N} \approx 10000 / \mathrm{rep} \\
& \\
& \times 3(\mathrm{FLT})\end{aligned}$ \\
\hline
\end{tabular}




\subsection{Comparative Analysis Reveals Key Differences in Space Flown Slow and Fast Twitch Muscle}

We first characterized the effects of spaceflight on fast and slow twitch muscle types (EDL and soleus, respectively) from the RR-1 Mission (Figure 1). Differential expression analysis (DEA) of EDL and soleus from space flown mice compared with ground controls along with ORA and GSEA are found in Supplementary Tables S1-S6, Networks S1 and S2 and Figures S1 and S2, respectively. Genes with the largest changes to their expression can provide insight on important biological processes that underlie spaceflight responses. Included in the top 10 upregulated genes in the EDL was the long non-coding RNA (Lncbate10) that has been shown to protect Pgc1 $\alpha$ from repression [44], as well as Mettl21e which inhibits proteasomes [45]. We also observed upregulation of the cell cycle-related gene C $d k 1$ and Mmp12, which play a role in ECM remodeling. The top downregulated genes included Pde2a, a phosphodiesterase (PDE), which controls degradation of cAMP and cGMP; the downregulation of Pde2a suggests increased cAMP/cGMP signaling. Downregulated as well was Lep, involved in energy homeostasis, and Pck1, a regulator of gluconeogenesis. Additionally, we found downregulation of Stum, which functions in mechanotransduction. Enriched results for the EDL show a response to radiation and reactive oxygen species (ROS) and the induction of apoptosis. In addition, there was enrichment of inflammatory pathways including Stat and $N f-\kappa b$, a response to wound healing and immune-related gene sets (GO:0045087, GO:0034097) involving the production of cytokines TGF $\beta$, IL4, IL10, and type 1 interferon. Enrichment of genes related to glucocorticoid (GC) signaling, a stress response pathway, was also observed. We found overrepresentation of gene sets involved in the circadian rhythm (GO:0048511, GO:0007623) as reported previously [22,46-48], including downregulation of $D b p$, a key circadian rhythm gene involved in inducing the transcription of other clock genes such as $m$ Per1 [49]. GSEA results also show enrichment of carbohydrate metabolism, consistent with previous studies reporting a greater reliance on glucose and a shift away from lipid metabolism [50]. In addition, we found downregulation of lipid metabolism (GO:0006631) based on ORA of downregulated genes Lep, Lpl, and Ppary [51-53]. Analysis also revealed enrichment of lipid transport and sequestration in the EDL, consistent with previously reported lipid accumulation in atrophied muscles [50]. ORA of upregulated DEGs in the EDL show proliferation-related gene sets (GO:0008283, GO:0000278) suggesting an increase in proliferation. Conversely, GSEA revealed enrichment of mitogenic signaling pathways (MAPK), which correspond to the upregulation of genes involved in cell cycle progression (Cdk1). GSEA also revealed regulation of proliferation and migration of vascular endothelial cells and angiogenesis (Supplementary Network 1, Supplementary Figure S1), suggesting spaceflight-induced changes to muscle vasculature. Results also show the enrichment of muscle cell development, and differentiation as well as upregulation of Fos, Mettl21e and Prnd, genes involved in differentiation and the upregulation of Pax3, a stem cell marker expressed in activated satellite cells.

In the soleus, the top upregulated genes consist of keratins, known to be important structural proteins in muscle as well as Mettle21e, involved in ECM remodeling, also found to be upregulated in the EDL. Dhrs9, involved in vitamin A biosynthesis, was downregulated, consistent with the observation of a reduction in retinol in lipid droplets in the liver of space flown mice [54]. Analyses also revealed downregulation of Gcat, which plays a role in threonine metabolism. Similarly, we found downregulation of $C 9$, which functions in the innate immune response. Enriched results for the soleus suggest stress signaling with the enrichment of a response to GCs (GO:0051384) and the downregulation of Ciart, a circadian gene with a role in the transcriptional repression of Clock and Bmal1 [55]. There were fewer immune related results in the soleus compared to the EDL (sole enrichment of interferon gamma and downregulation of $I l 8$ in the soleus). These results may suggest that the EDL has a more robust immune response than soleus, consistent with findings from a previous spaceflight study [56]. Further, GSEA indicated negative regulation of the unfolded protein response (UPR), suggesting downregulation of endoplasmic reticulum (ER) stress response in the soleus. Metabolic changes also differ in comparison to the EDL, with results indicating an increase in protein metabolism (GO:0006082, GO:0019752, 
GO:0072330) using upregulated genes in ORA. This is accompanied by negative correlation of ribosome biogenesis and negative nucleotide biosynthesis with spaceflight, all consistent with a decrease in muscle mass. While mixed results were reported for the regulation of lipid metabolism, the results suggest a decrease in glucose metabolism (GO:0005975). We also found enrichment of growth related gene sets such as upregulation of growth hormones including Igf1 and its receptor, Igf1r. However, findings also included negative cell growth (GO:0016049) and proliferation (GO:0008283). The presence of positive and negative growth pathways may suggest remodeling of the muscles as they respond to the need to replenish and remove old or damaged cells in response to spaceflight. Similarly, results using up- and downregulated genes in ORA also indicate both positive and negative developmental cues including the enrichment of negative tissue development (GO:0009888) and cell differentiation (GO:0045595). A cross comparison of the biological processes shared between the EDL and soleus is shown in Figure 2, and shared DEGs are presented in Supplementary Table S7.

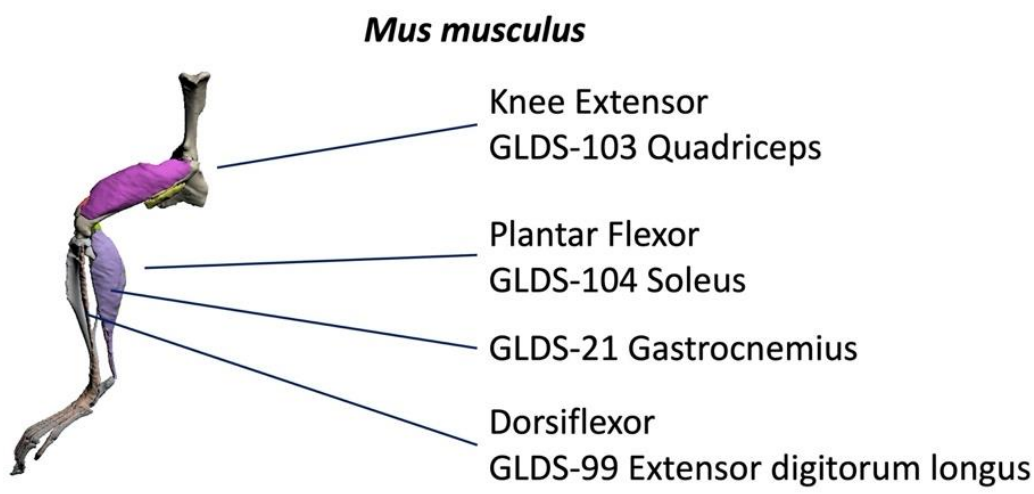

Type I Slow Type II Fast

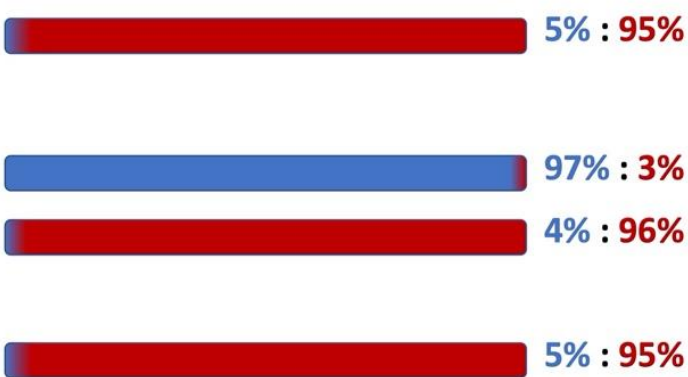

Homo sapiens

GSE24215 - Vastus lateralis

$41 \%: 59 \%$

Figure 1. Anatomical positions of the various mouse and human muscles used in this study, grouped by function. The right panel shows the percentage of slow and fast twitch fibers for each muscle. 


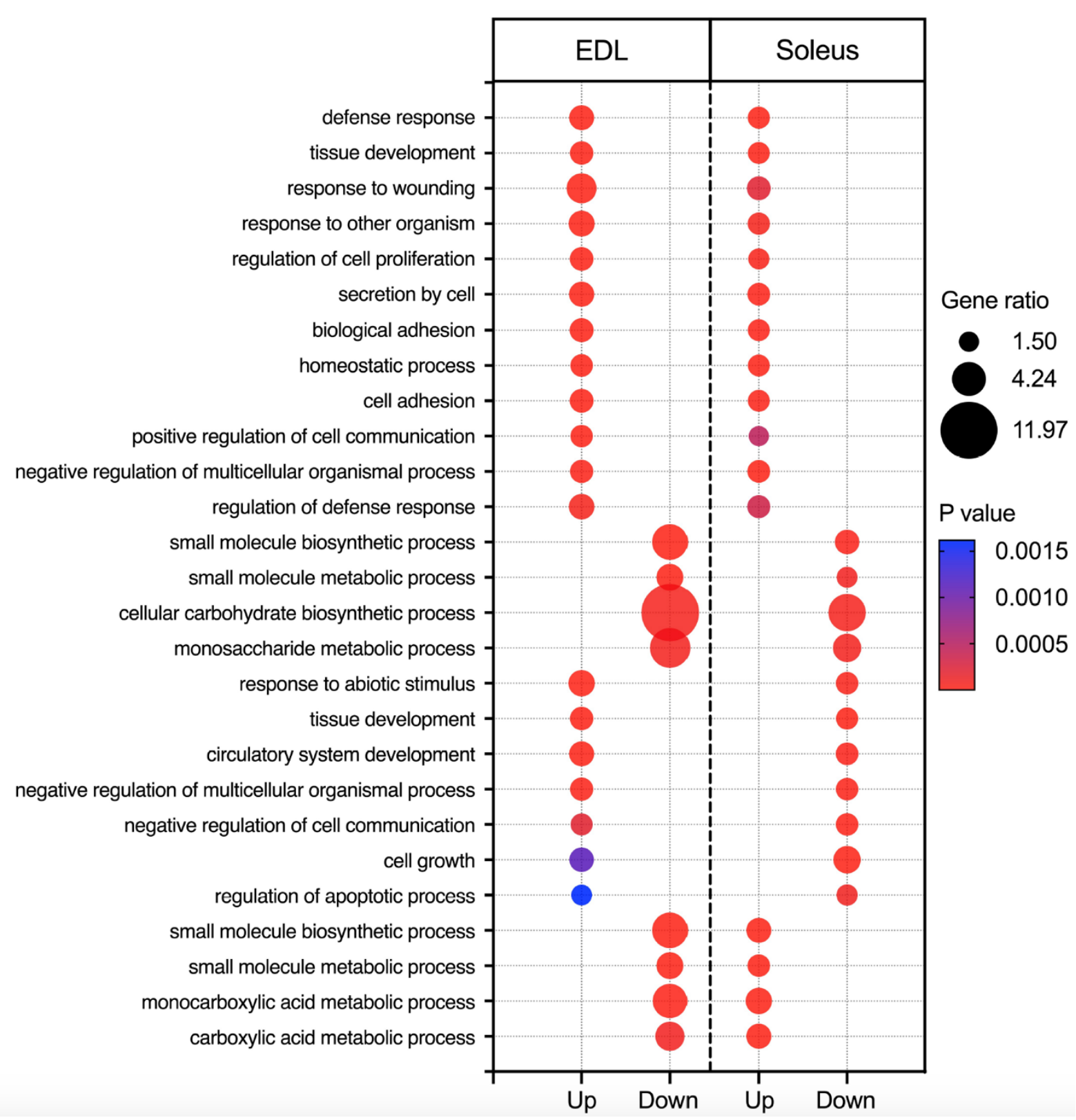

Figure 2. Shared upregulated and downregulated biological processes in soleus and EDL in response to spaceflight. The resulting gene ratio and $p$ values from Webgestalt analysis of DEGs are shown.

2.3. Molecular Signatures of C. elegans in Comparison with Fast and Slow Twitch Muscles during Spaceflight

2.3.1. Shared Increase in Proliferation between Space Flown C. Elegans and Mouse Fast Twitch EDL

We next asked whether invertebrate models can be used to gain insight into mammalian responses to spaceflight. To address this question, we performed ORA on space flown C. elegans and utilized Ensembl orthology [57] to perform a cross-species comparison with mouse muscles to assess whether the transcriptional responses to spaceflight found in mammalian muscle are also observed in nematodes. DEGs and ORA can be found in Supplementary Tables S8 and S9. Differential expression analysis of space flown C. elegans revealed 106 DEGs (FDR < 0.05). Initial inspection of the enriched biological processes of $C$. elegans revealed that most upregulated biological processes (BP) are related to cell division (GO:0007049, GO:0051301) and development (GO:0032502), processes akin to the phenotype defined in the EDL. We also found upregulation of genes related to 
cytoskeleton organization (GO:0000226, GO:0007010), chitin metabolism (GO:0006030), and downregulation of ECM organization (GO:0030198). A cross-comparison between C. elegans and EDL enriched biological processes, shown in Figure 3, also indicates the shared overrepresentation of proliferation-related gene sets (GO:0008283, GO:0000278, GO:0022402). Gene sets related to the immune response (GO:0006955), synaptic signaling (GO:0098916) and the ECM (GO:0030198) were upregulated in the EDL but downregulated in C. elegans. A comparison of C. elegans and EDL DEGs revealed seven shared genes. These include an oncogene with a role in cell polarity (Cab39) [58] and a gene involved in base excision repair (Ung) [59]. An early development gene Zcchc24 [60] was downregulated in both datasets. In addition, we found downregulation of Rab20, a gene involved in cell trafficking in the Golgi apparatus [61], consistent with downregulation of cell-cell signaling (GO:0007267). Genes upregulated in C. elegans but downregulated in the EDL have roles in uracil methylation (Trmt44), calcium-mediated synaptic transmission (Syt12), and thrombin degradation $(T h b d)$.

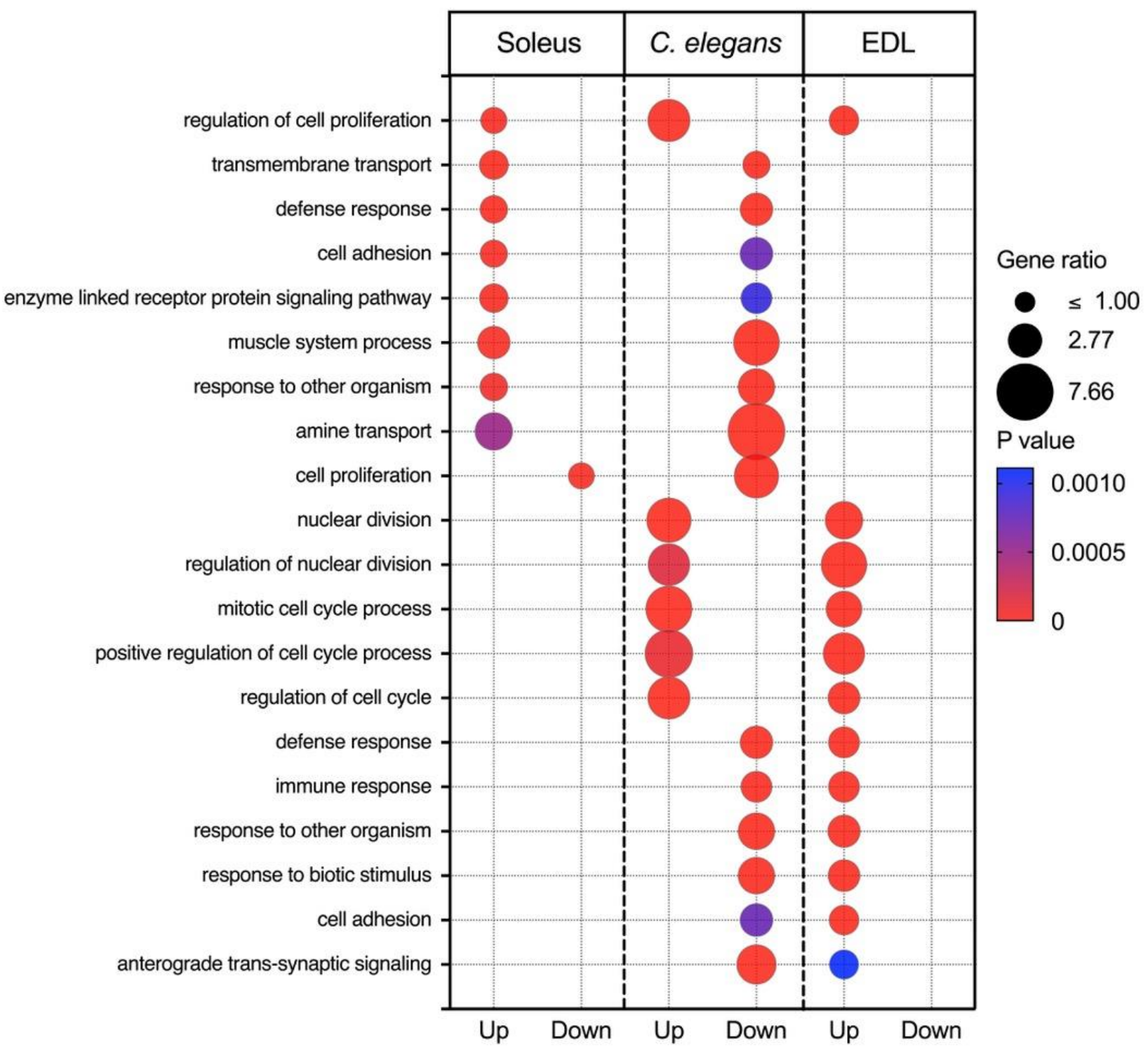

Figure 3. Shared upregulated and downregulated biological processes in C. elegans compared with soleus and the EDL in response to spaceflight. The resulting gene ratio and P values from Webgestalt analysis of DEGs are shown. 


\subsubsection{Comparison between C. elegans and Mouse Slow Twitch Muscle, Soleus}

Similar to findings from comparisons with EDL, we also found shared biological processes between C. elegans and soleus (Figure 3), namely downregulation of cell proliferation. However, other processes were regulated in opposite directions. Specifically, transmembrane transport (GO:0055085), defense response (GO:0006952, GO:0098542), and cell adhesion (GO:0007155) were downregulated in C. elegans, yet upregulated in the soleus. We found 16 shared DEGs in C. elegans and soleus (Table 2). Upregulated in both C. elegans and soleus are mitochondrial genes involved in mtDNA repair (Mpv17), branched chain amino acid metabolism (Ppm1k) [62], and the DNA helicase gene Mcm2. Shared downregulated genes include Thbd, involved in thrombin degradation as well as Rab20, previously described. Genes that were upregulated in C. elegans but downregulated in the soleus include those involved in DNA repair (Nsmce1) [63], and the unfolded protein response (Shq1), suggesting increased damage response in C. elegans. Genes that are downregulated in C. elegans but upregulated in the soleus are involved in muscle excitability (Ric3) [64] and synaptic signaling (Syt12, Ric3, Htr7) [64-66] which may impact muscle contraction if globally upregulated in neurons. Downregulated in C. elegans were Dpp4, a gene encoding a multi-functional transmembrane protein involved in glucose uptake [67], and Plce1 involved in growth and differentiation [68]. Pde4b, which codes for an enzyme that degrades cAMP to AMP, was downregulated, suggesting increased cAMP signaling in C. elegans, which is more akin to the EDL response.

Table 2. DEGs shared between space flown C. elegans and soleus muscle and their direction of regulation. Values shown are Log2 fold change (FC).

\begin{tabular}{ccc}
\hline Genes & C. elegans & Soleus \\
\hline & Both upregulated & \\
Mcm2 & 0.4 & 0.38 \\
Ppv17 & 0.39 & 0.32 \\
Ppm1k & 0.33 & 0.58 \\
\hline & Both downregulated & \\
Rab20 & -0.4 & -0.48 \\
Thbd & -0.64 & -0.45 \\
\hline & Opposite regulation & \\
Nsmce1 & 0.5 & -0.41 \\
Tmem205 & 0.39 & -0.78 \\
Shq1 & 0.36 & -0.36 \\
Exosc3 & 0.33 & -0.34 \\
Ppp4r4 & -0.32 & 1.63 \\
Syt12 & -0.32 & 0.72 \\
Dpp4 & -0.36 & 0.55 \\
Ric3 & -0.37 & 0.49 \\
Htr7 & -0.38 & 0.77 \\
Plce1 & -0.5 & 0.39 \\
Pde4b & -0.51 & 0.73 \\
\hline
\end{tabular}

2.4. Cross-Comparison between Space Flown D. melanogaster and Mouse Muscles

2.4.1. Shared Stress Response in EDL and Larval D. melanogaster

We also determined whether space flown $D$. melanogaster share any similarities with mammalian muscle responses spaceflight. To determine this, we individually compared EDL with larvae and adult $D$. melanogaster. We reasoned that doing such may provide insight into any life-stage dependencies in our findings. DEA of space flown D. melanogaster larvae revealed 439 orthologous mouse genes (Supplementary Table S10), which were subjected to ORA (Supplementary Table S11). Genes were compared with mouse EDL, revealing 18 shared DEGs shown in Table 3. Shared upregulated genes include the circadian rhythm gene Noct, consistent with previous observations in space flown D. melanogaster [69]. Stress-induced molecular chaperones (Hsp90aa1) were also upregulated as well as genes 
involved in the biosynthesis of carnitine and fatty acid transport (Tmlhe). Shared downregulated genes include Mettl26, a methyltransferase. Genes with opposing patterns of regulation reveal key differences in metabolism including $D 2 h g d h$, upregulated in $D$. melanogaster, involved in D2-HG metabolism in the mitochondria, and Cth, involved in cysteine biosynthesis. Genes that were upregulated in the EDL but downregulated in D. melanogaster suggest differential regulation of glycosylation (Gmppb), the cytoskeleton (Tubb4b) and ECM organization (Hspg2, Prcp), blood pressure (Prcp), and protein ubiquitination (Plaa).

Table 3. DEGs shared between space flown D. melanogaster and EDL and their direction of regulation. Values shown are Log2 FC.

\begin{tabular}{ccc}
\hline Genes & Larval D. melanogaster & EDL \\
Tmlhe & Both upregulated & \\
Noct & 0.99 & 0.34 \\
Hsp90aa1 & 0.61 & 0.59 \\
& 0.51 & 0.53 \\
Chac1 & Both downregulated & \\
Mettl26 & -0.91 & -1.61 \\
& -0.43 & -0.38 \\
Amdhd2 & Opposite regulation & \\
Adck5 & 0.4 & -0.46 \\
D2hgdh & 0.37 & -0.5 \\
Cth & 0.85 & -0.32 \\
Surf6 & 0.49 & -0.5 \\
Tubb4b & 0.56 & -0.39 \\
Gmppb & -0.36 & 0.53 \\
Ypel2 & -0.33 & 0.33 \\
Prcp & -1.15 & 0.65 \\
Cotl1 & -0.59 & 0.32 \\
Plaa & -0.7 & 0.41 \\
Timm9 & -0.36 & 0.32 \\
Hspg2 & -0.42 & 0.42 \\
\hline
\end{tabular}

2.4.2. Shared Responses of Larval D. melanogaster and Soleus from Space Flown Mice

A comparison of larval D. melanogaster DEGs revealed 61 shared genes with the soleus (Supplementary Table S12). ORA of the 38 upregulated orthologs (Supplementary Table S13) suggested a shared increase in protein metabolism (GO:0006520, GO:0000096, GO:0006534). Notably, both datasets include the downregulation of Pdia6, which promotes proliferation $[70,71]$ and a mitochondrial gene, Gtpbp3, for which studies involving its knockdown reported reduced ATP generation, increased ROS, and apoptosis [72]. The molecular chaperones Hspa5 and Hspb6 were also downregulated, suggesting a reduction of UPR signaling and consistent with increased protein metabolism, features observed in the soleus. Scarb1 was downregulated in both soleus and D. melanogaster larvae. SCARB1 has been shown to play an important role in muscle regeneration [73]. Similarly, Crym was downregulated, knockout of which in mice leads to hypertrophy of fast glycolytic fibers [74]. Pnf4, important for actin polymerization [75] was also downregulated in both soleus and $D$. melanogaster larvae.

2.4.3. Comparison of Space Flown Adult D. melanogaster and Fast Twitch Mammalian Muscles

We next compared adult $D$. melanogaster to the mouse muscles. Spaceflight led to 459 DEGs $($ FDR $<0.05$ ) in adult D. melanogaster (Supplementary Table S14). Of these, we found 101 that are orthologous to mouse genes, which were used for ORA (Supplementary Table S15). Four of the DEGs were found to be shared with the mouse EDL dataset. Genes that showed 
upregulation of expression in the two datasets were found to be involved in chromatin scaffolding (Ppp1r10) and replication (Mcm6). Ppm1l, downregulated in both datasets, is a negative regulator of stress and inflammatory cytokines. Hence, its downregulation in the EDL is consistent with an increased immune response [76]. Also dysregulated was Hspg2, which encodes an ECM protein.

\subsubsection{Comparison of Space Flown Adult D. melanogaster with Mouse Soleus}

A comparison of adult D. melanogaster DEGs with soleus DEGs (FDR $<0.1$ ) revealed 12 shared genes shown in Table 4. Genes that are upregulated in both datasets include a myosin protein ligase (Mylip) involved in muscle atrophy, previously reported to be induced by glucocorticoids [77]. Also upregulated were genes encoding a helicase protein $M c m 2$ involved in replication and the pro-survival gene, Ppm11, which negatively regulates SAPK-mediated apoptosis. However, Jarid2 was also upregulated in both, which represses pro-cell cycle genes [78]. Additionally, $\mathrm{Cbs}$ which takes part in the transulfuration pathways in cysteine production, is also upregulated. Genes that are downregulated in both datasets encode a nucleoporin (Nup37), a polymerase (Polr2e) and Dnajb4, the suppression of which has been linked to decreased growth [79]. Genes upregulated in D. melanogaster but downregulated in mouse soleus include the helicase subunit (Mcm6) and genes involved in cysteine production (Gnmt), calcium signaling (Inpp5a), and limb development (Fjx1).

Table 4. DEGs shared between space flown adult D. melanogaster and soleus muscle and their direction of regulation. Values shown are Log2 FC.

\begin{tabular}{ccc}
\hline Genes & Adult D. melanogaster & Soleus \\
\hline & Both upregulated & \\
Mylip & 0.7 & 0.41 \\
Ppm1l & 0.69 & 0.46 \\
Mcm 2 & 0.69 & 0.38 \\
Cbs & 0.42 & 2.09 \\
Jarid2 & 0.89 & 0.39 \\
\hline & Both downregulated & \\
Nup37 & -0.33 & -0.39 \\
Polr2e & -0.36 & -0.47 \\
Dnajb4 & -0.33 & -0.41 \\
\hline & Opposite regulation & \\
Gnmt & 0.72 & -0.6 \\
Inpp5a & 0.44 & -0.86 \\
Fjx1 & 0.41 & -0.54 \\
Mcm6 & 0.37 & -0.79 \\
\hline
\end{tabular}

2.5. Comparison between Ground-Based Unloading Models and Muscles from Space Flown Mice 2.5.1. Comparison between Gastrocnemius from Hindlimb Unloaded and Space Flown Mice

To gain insight on shared transcriptomic signatures of ground-based unloading models and space flown mice, a transcriptomic analysis was conducted on RNA of gastrocnemius from space flown mice and a time and age-matched HU study (GLDS-21). Analyses revealed 75 DEGs $(p<0.05)$ in the gastrocnemius from hindlimb unloading $(\mathrm{HU})$ mice (Supplementary Table S16) and 115 DEGs $(p<0.05)$ in the gastrocnemius from space flown mice (Supplementary Table S17). The top upregulated genes in the HU model have roles in UPR (Hspa1b, Hspa1a, Atsf3), and fatty acid biosynthesis and metabolism (Fasn, Ppargc1a). Proto-oncogenes Fos and Jun were also upregulated in HU mice. In contrast, a previous study reported upregulation of Fos and Jun in human muscle after exercise [80]. Additionally, the top 10 most downregulated genes include mitochondrial genes such as $I d h 2$, which takes part in the electron transport chain, $B d h 1$ involved in ketone metabolism, and $L d h b$, which catalyzes the conversion of pyruvate to lactate. ORA performed on DEGs from gas- 
trocnemius of HU mice (Supplementary Table S18) revealed differential regulation of stress responses (GO:0033554, GO:0009628), as well as muscle tissue proliferation (GO:0048659), differentiation (GO:0035914) and development (GO:0007519).

Conversely, the top upregulated genes in the gastrocnemius from space flown mice include $M t 1$ and $M t 2$, genes that have antioxidant activity and glucocorticoid response elements [81]. We also found upregulation of a number of tumor suppressor genes such as Btg2, Cebpd, Gadd45g, Cdkn1a and Tp53inp1 [82-86], suggesting reduced growth and proliferation. Cidec, which codes for a protein that promotes lipid droplet formation in adipocytes [87], was also upregulated. ORA of upregulated DEGs in spaceflight gastrocnemius (Supplementary Table S18) suggests a stress response as shown by differential regulation of GC signaling (GO:0071385). ORA also revealed upregulation of glucose metabolism (GO:0032868) in the gastrocnemius from space flown mice, suggesting alterations in energy homeostasis.

A comparison of DEGs in HU and spaceflight gastrocnemius revealed five shared genes with similar patterns of regulation. DEGs upregulated in both datasets suggest that $\mathrm{HU}$ and spaceflight both lead to altered circadian rhythm (Nfil3), regulation of proliferation (Btg2) and changes to endothelial adhesion (Cyr61), and scaffolding of acetylcholine receptors at the neuromuscular junction (Musk), which may potentially alter muscle function. Additionally, $B d h 1$, a gene involved in metabolism of ketone bodies, is downregulated in both datasets. This is consistent with a previous study showing an increase in ketone bodies such as 3-hydroxybutyrate in liver of mice flown on STS-135 [54].

\subsubsection{Comparison of Muscles from Bed Rest Study and Space Flown Mice}

Next, we investigated shared transcriptomic responses between representative mixed fiber type muscles, and vastus lateralis muscles $(\mathrm{VL})$ obtained from a bedrest study (NCBI GEO GSE24215/GLDS-370) (349 DEGs, \pm 1.5 FC, $p<0.05$, Supplementary Table S19) versus quadriceps of space flown mice (887 DEGs, $p<0.05)$, Supplementary Table S20). Eight genes were shared between these datasets (Table 5). Upregulated in both datasets was Tbc1d12 involved in increasing glucose uptake [88], whereas the shared downregulated genes included Ptp4a3, the downregulation of which increases expression of ECM genes [89], and Fbxo40, the downregulation of which has been observed in muscular dystrophy [90]. Additionally, Ssmpx, a gene induced by stretching of muscles, was downregulated in the human VL but upregulated in mouse quadriceps [91]. ORA of DEGs in human VL (Supplementary Table S21) revealed downregulation of nucleotide metabolism (GO:0009117, GO:0006753) and oxidation-reduction processes usually associated with oxidative phosphorylation (GO:0055114). Conversely, ORA results for mouse quadriceps (Supplementary Table S22) showed downregulation of protein metabolism (GO:0030163, GO:0044257, GO:0051603, and GO:0006511) and a response to stress (GO:0033554).

Table 5. DEGs shared between human bedrest VL and space flown mouse quadriceps and direction of expression. Values shown are Log2 FC.

\begin{tabular}{ccc}
\hline Genes & Vastus Lateralis & Quadriceps \\
\hline & Both upregulated & \\
Tbc1d12 & 0.84 & 0.29 \\
Lonrf3 & 1.09 & 0.7 \\
\hline & Both downregulated & \\
Ptp4a3 & -1.26 & -0.61 \\
Mbst3 & -1.11 & -0.41 \\
C7orf50 & -1.1 & -0.17 \\
& -0.89 & -0.46 \\
Smpx & Opposite regulation & \\
Hccs & -1.09 & 0.30 \\
\hline
\end{tabular}




\section{Discussion}

\subsection{Mechanisms of Muscle Atrophy Resistance}

Skeletal muscles are highly adaptive to changes in mechanical forces and display a robust regenerative capacity. In response to weight-bearing or cell damage, cells can initiate pro-survival signaling pathways that increase cell viability and growth, maintain cell number homeostasis, and allow proliferation to meet functional needs. Analysis of the transcriptomic response in the EDL from space flown animals reveals enrichment and overrepresentation of gene sets involved in necrosis, wound healing, immune response, and proliferation, which altogether may suggest a compensatory proliferation in reaction to cell damage. Since mature muscles cells do not divide, the enrichment of proliferative terms may represent the recruitment of satellite cells, which then differentiate into new myofibers [92] to achieve muscle regeneration after cellular insult [93]. This hypothesis is supported by enrichment of developmental GO terms and the upregulation of genes such as Fos and Pax3 known to be expressed in activated satellite cells during muscle cell development and in early muscle regeneration post trauma [94,95]. Previous studies also show tissue regeneration markers of satellite cell activation in murine quadriceps during spaceflight [96]. Spaceflight and its analogs can lead to impaired immunity [97-102]. A more robust immune response in the EDL may also indicate damage and repair events in this muscle, given the role the immune system plays in the regeneration process $[103,104]$. In the EDL, the upregulation of $I l 15$, which codes for an immune modulating cytokine previously noted to confer hypertrophic effects. Increased Il15 expression may contribute to regeneration and prevent excessive atrophy in response to unloading [105]. Additionally, these results also suggest changes to vasculature, which may impact nutrient availability and therefore growth. Previous work on the HU model revealed impaired vasodilation [106] and vasoconstriction [107] in feed arteries of weight bearing plantar flexors. Similarly, radiation exposure has been shown to impact development in human vessel models [108]. The involvement of the above mentioned differentially expressed genes in skeletal muscle atrophy can be tested in future spaceflight experiments.

A genetic mechanism that may contribute to the difference in sensitivity to atrophy between the EDL and soleus may involve regulation of PDEs, which hydrolyze and tightly control cAMP/cGMP. cAMP/cGMP are ubiquitous second messenger signaling molecules known to protect against atrophy, increase myofiber size, and promote conversion to faster glycolytic fibers [109]. Our results showed downregulation of phosphodiesterase genes $(P d e 2 a)$ in the EDL suggesting increased cAMP/gAMP signaling. In contrast, the upregulation of Pde2a, along with five other phosphodiesterase genes (Pde3a, Pde4a, Pde4b, $P d e 4 c, P d e 9 a)$ in the soleus suggests decreased cAMP/cGMP signaling. Further work is needed to define levels of cAMP signaling in different muscle types during spaceflight and whether this pathway can be exploited to prevent muscle atrophy during spaceflight. Additionally, in the EDL, a long non-coding RNA (Lncbate10) was upregulated, which is known to protect $P g c 1 \alpha$ from repression in adipose tissues [44]. This coincides with the upregulation of $P g c 1 \alpha$, a gene whose expression is also known to protect against atrophy [110]. The expression of Lncbate10 has been shown to be induced by high cAMP concentrations, consistent with the downregulation of the cAMP regulator, Pde2a [44]. Spaceflight is known to induce slow-to-fast muscle fiber conversion [111]. In addition to Pgc1 $\alpha$ upregulation in the EDL, we also observed the upregulation of Mettl21e, both of which are known to drive hypertrophy of type II myofibers [45,112]. Additionally, we observed the downregulation of Vegfa in the soleus, which was not observed in the EDL. This suggests opposing regulation of a key growth signal in vasculature of the two muscle types, which influence nutrient availability and ultimately, the propensity for muscle growth.

\subsection{Glucocorticoids and the Circadian Rhythm}

The enrichment of glucocorticoid (GC) signaling suggests that spaceflight led to upregulation of the stress response. This is consistent with the reported rise in plasma 
and urine cortisol levels observed in certain but not all of spaceflight studies [113,114]. GCs are steroidal signaling molecules with many roles including the regulation of energy homeostasis. They can cause the breakdown of amino acids and a decrease in insulin sensitivity, which were previously observed in the soleus [115]. GCs can also induce expression of clock genes via GC response elements and may therefore have a role in perturbing the circadian rhythm and sleep cycles during spaceflight [22,116-118]. The disturbance of the circadian rhythm in both muscles (EDL and soleus) may also negatively impact muscle mass. For example, knockout of a key circadian gene, Bmal in mice led to premature aging including sarcopenia [119]. Perturbations in GC and the circadian signaling have been implicated in disorders such as metabolic syndrome, [120-122], sleep disturbances [123,124], immune dysregulation [100,125,126] and cataracts [127]. Hence, these signaling pathways may potentially represent therapeutic targets for the detrimental effects of spaceflight.

\subsection{Spaceflight Alters Mechanosensing and Neuronal Signaling in Mouse Muscle}

Transcriptomic analysis of muscles from space flown mice revealed alterations in signaling pathways involved in mechanotransduction and neuromuscular communication. For example, results showed downregulation of Stum in the EDL, which encodes a protein important for the sensing of mechanical stimuli in proprioceptive neurons [128]. This finding is consistent with the effects of unloading and reduced proprioception observed during spaceflight $[128,129]$. Similarly, we observed enrichment of genes involved in Rho signaling, one of the pathways that can promote stress fiber formation [130]. Contractility changes in stress fibers is thought to be one the mechanisms by which mechanical forces exerted on the extracellular matrix (ECM) can be sensed by a cell [131]. We also found differential expression of a number of genes involved in neuron excitability such as Grin2b, the dysregulation of which leads to decreased muscle tone [132]. In the soleus, the enrichment of gene sets involved in nervous system development and negative axon extension and the downregulation of neurogenesis (GO:0022008) suggest changes to motor neuron signaling.

\subsection{C. elegans Shows Similarity to Mouse Fast Twitch Muscle Responses to Spaceflight}

Rodents have been widely used to extrapolate human responses to spaceflight due to their significant genetic, physiological, and anatomical similarities. C. elegans, however, have been widely used to study developmental processes since at least $83 \%$ of the proteome has a human homologue and $\sim 8000$ of its proteins have matching human gene transcripts [133]. The use of C. elegans as a spaceflight model has advantages over rodent models such as their relatively simpler maintenance requirements and smaller body size that allows for a larger number of individuals to be flown in space. In addition, C. elegans allows the use of genetic and molecular tools to dissect specific pathways and can be used for the analysis of potential countermeasures. A caveat of our comparison is that the transcriptomics was performed on a population of animals of mixed ages, and that nematodes contain multiple tissues-neurons, gut, reproductive tissue, in addition to muscles. Understanding how responses in C. elegans mirror mammalian responses to spaceflight may allow for better extrapolation to mammalian results. While the comparison between C. elegans and mouse muscles revealed differences in spaceflight-induced regulation of developmental genes, there was a shared increase in proliferation-related terms with the more atrophy resistant EDL. Similarly, we posit that C. elegans may resist muscle atrophy through shared increased cAMP signaling as indicated by the downregulation of Pde4b, encoding a cAMP regulatory enzyme, variants of which were upregulated in the soleus. The more proliferative transcriptomic signature in C. elegans is more similar to that of the EDL, suggesting shared mechanisms of resistance and may point to a utility for the organism in anticipating responses of fast twitch muscle fibers. Additionally, while C. elegans have been used for uncovering mechanisms of innate immunity analogous to humans, their immune response to spaceflight was not comparable to that seen in fast or slow twitch muscle. This may be due to the lack of an adaptive immune system in C. elegans [134]. 


\subsection{Discrete Life Stages of D. melanogaster May Have Distinct Utility for Studying Muscle Types}

Establishing shared responses to spaceflight between D. melanogaster and mammalian muscles also may be of value in anticipating mammalian responses to spaceflight. $D$. melanogaster are desirable as flight payloads due to their relatively small experimental footprint and their ease of maintenance. A comparison between different life stages of $D$. melanogaster and mammalian fast and slow twitch muscles revealed that discrete fly life stages may have differing utility for modeling certain features of the response to spaceflight in these mammalian muscle types. For example, an increase in protein metabolism as well as the downregulation of the UPR, two key features of the soleus response, were observed in D. melanogaster larvae. Conversely, protein metabolism was downregulated in adult $D$. melanogaster and not observed in the fast twitch EDL. This may suggest stage-dependent differences in metabolism. Moreover, other features of mature adult D. melanogaster are more akin to the fast twitch muscle, including an increase in amino acid production, calcium signaling and limb morphogenesis suggesting an environment with more growth signals. With regards to metabolism, the increase in expression of genes involved in fatty acid transport in adult D. melanogaster is akin to that of the EDL. However, adult $D$. melanogaster also shows a shared degradation of myosin protein with slow twitch muscle EDL. Furthermore, we also found a similar stress response between space flown adult D. melanogaster and mouse fast twitch muscle as indicated by differential regulation of circadian rhythm and antioxidant response genes.

Spaceflight and analog studies using D. melanogaster may allow for greater mechanistic insight on muscle gene regulation under spaceflight conditions. To date, on-orbit sampling of invertebrate models has mostly involved whole animals due to the logistical challenges of performing microdissections of tissues. Transcriptomic signatures can vary across muscle types and such differences may not be captured when analyzing the overall transcriptome from the whole organism. For example, each muscle type in D. melanogaster has a discrete pattern of isoform expression of Troponin, which regulates thin filament contraction $[30,135]$. We found that these isoforms are also differentially expressed in both spaceflight and analog experiments, consistent with a previous report [30]. Advances in sample preservation and in situ dissections on orbit will greatly improve our ability to gain mechanistic knowledge from smaller model organisms.

\subsection{Differential Regulation of ECM in Spaceflight across Organismal Models}

Our results indicate differential regulation of ECM-related processes in C. elegans, D. melanogaster, and rodent EDL in response to spaceflight. Specifically, C. elegans showed downregulation of ECM organization and cell adhesion gene sets while these were upregulated in the EDL. Similarly, there was downregulation of ECM genes Hspg2, Prcp in larval D. melanogaster, while these genes were upregulated in the EDL. Hspg2 encodes Perlecan, which is involved in ECM organization [135]. PRCP activates Prekallikrein, which cleaves fibronectin, a component of the ECM [136]. Hspg2 was also differentially regulated in adult D. melanogaster. Comparison of vastus lateralis from bedrest and quadriceps from space flown mice also revealed a shared upregulation of Ptp $4 a 3$, the downregulation of which increases expression of ECM genes [89]. These results suggest a general trend of increased expression of ECM-related genes in rodents and humans compared to downregulation in smaller model organisms such as D. melanogaster and C. elegans. The ECM plays important roles in a plethora of biological processes ranging from growth, migration, structural organization, barrier formation, and the immune response [137]. It is also impacted by spaceflight or simulated microgravity, as part of the mechanotransduction pathways involving integrins and mechanically activated ion channels [138]. The differences in the direction of regulation of ECM-related genes may be due to differences in body or tissue structure (hence differing ECM composition) and the differences in the timing of sampling and duration of flight. However, differential expression of ECM-related genes in all spaceflight models and analogs tested in this study suggest that ECM remodeling is likely to be a universal response to spaceflight. 


\subsection{Transcriptomic Signatures of Spaceflight Models and Analogs Exhibit Similarities and Key Differences}

Ground-based analogs such as HU have proven useful in anticipating many aspects of the musculoskeletal response to microgravity. Analysis of the transcriptome of the gastrocnemius from space flown rodents and a time-matched HU study revealed differences in transcriptomic signatures between these two models, particularly in the direction of regulation of genes involved in cell proliferation, circadian rhythm, endothelial cell adhesion, and motor neuron signaling. These changes are consistent with musculoskeletal atrophy, gait changes, sleep disturbances, and altered vascular function in humans that experienced spaceflight. However, we recognize that experimental limitations may impact comparative analysis of ground-based and spaceflight studies in rodents. Specifically, differences in animal handling and housing of space and ground-based rodent models can potentially affect the results. The use of appropriate housing controls and introduction of manipulations in controls that consider the additional handling associated with sending payloads to space (e.g., transport in ground vehicles, landing forces, light-dark cycle changes) may minimize the confounding factors when comparing findings from ground-based versus spaceflight rodent studies.

We also compared muscles from a rodent spaceflight and human bedrest study, two of the relatively resource intensive approaches to modeling human responses to spaceflight. Both have key advantages relative to ground-based rodent models. The former is expected to reflect mammalian responses to actual spaceflight and the later, actual human physiological responses to unloading. We found that representative mixed fiber type muscles in $\mathrm{HU}$ mice and humans on bedrest (quadriceps and VL, respectively) share similarities in differential expression of Tbc1d12, a gene involved in glucose uptake. In addition, Fbxo40, a gene that is also upregulated in a denervation model for muscle atrophy [90] is similarly responsive to both spaceflight in rodents and bedrest. Further, FBXO40 functions as a muscle-specific E3 ubiquitin ligase that is regulated by activated STAT3, thereby increasing insulin resistance in mice under $1 G$ conditions [139]. Upregulation of both Tbc1d12 and Fbxo40 in bedrest and rodent spaceflight models is consistent with reported perturbations in glucose metabolism observed in humans in space [140]. These findings provide a rationale for testing whether targeting Fbxo40 and its signaling partners will be useful in mitigating muscle atrophy and altered glucose metabolism in both spaceflight and Earth-based scenarios.

\section{Materials and Methods}

\subsection{Datasets Used in This Study}

Table 1 lists the various datasets used in this study. These datasets can be found in NASA GeneLab and are cited in these references [24,25,37-41]. The datasets involving mice flown on the ISS make use of the NASA Rodent Research notation for the various experimental groups. Specifically, NASA RR-1 validation mice consisted of four groups to also enable assessment of the contributions of age and cage configuration. These include Spaceflight (FLT) and Ground Control (GC) groups, which both make use of the NASA rodent habitat. The GC group was run with a 4-day delay to allow for replication of actual temperature, gas partial pressures, and humidity conditions of the FLT group. In addition, a baseline (Basal) group was euthanized on Earth one day after launch to compare changes in both the FLT and GC groups. Lastly, a Vivarium (Viv) control comprising mice maintained in standard housing was also included to determine the impact of the mouse habitat hardware in the results obtained from the FLT and GC groups. Refer to [17] for further details. NASA GeneLab generated omics data from the following comparisons: Basal vs Viv controls, GC vs Viv controls, FLT vs GC [17]. In this work, we focus on the GC and FLT groups. A number of bedrest studies focusing on muscle have been published, with a variety of assay approaches (coding and non-coding RNA), main experimental variables, and tissue collection schemes [24,141,142]. For this current analysis, we selected 
a transcriptomic dataset from a previous bedrest study [24] based on availability of raw expression data from coding RNA.

\subsection{Processed RNAseq Data}

Differential expression data of RNA-seq datasets (GLDS-99, 103 and 104) were downloaded from NASA GeneLab. The NASA GeneLab online database describes the standard analysis pipeline used to generate this processed data. Briefly, the percentage of rRNA in raw fastq files was assessed using HTStream SeqScreener (version 1.0.0) and then filtered using Trim Galore! (version 0.6.2). The quality of both raw and trimmed reads was evaluated with FastQC [143] (version 0.118), while MultiQC [144] (version 1.7) was used to generate MultiQC reports. Indexes for Mus musculus genome were generated with genome version mm10-GRCm38 (Mus_musculus.GRCm38.dna.toplevel.fa), and Mus_musculus.GRCm38.96.gtf using STAR [145] (version 2.7.1a). Processed reads were aligned to the Mus musculus reference with STAR (version 2.7.1a) and aligned reads were then quantified using RSEM [146] (version 1.3.1). Quantification data was imported to R [147] (version 3.6.0) with tximport [148] (version 1.14.0) and normalized with DESeq2 [149] (version 1.26.0). Differential expression analysis was conducted in $\mathrm{R}$ (version 3.6.0) using DESeq2 (version 1.26.0). All groups were compared using the Wald test and the likelihood ratio test was used to generate the F statistic $p$ value. Gene annotations were assigned using the following Bioconductor and annotation packages: STRINGdb [150], PANTHER.db [151], and org.Mm.eg.db [152]. Differential expression analysis using DESeq2 [153] was performed on expression data from space flown subjects against ground controls to assess gene level changes in these muscles and use in downstream pathway analysis.

\subsection{Processing of Microarray Data}

For Affymetrix microarray datasets (GLDS-3 and GLDS-21), the raw expression data were downloaded from NASA GeneLab database. The data were normalized using the 'affyNormQC.R' $r$ script applying the RMA algorithm through the oligo R package with default parameters. The 'affyNormQC.R' $r$ script was also used to generate quality control with parameter 'do.logtranspaceflightorm' set to TRUE. The microarray experiments were annotated with the $\mathrm{r}$ script 'annotateProbes. $\mathrm{R}$ ', which employed Annotation-Db class probe annotations specific to the chip used in each experiment from the Bioconductor repository. In cases where multiple probes mapped to the same gene ID, representative probes were selected with the highest mean normalized intensity across all samples. The limmaDiffExp.R r script was used to perform differential gene expression analysis on normalized expression data to perform pair-wise comparisons for all groups. For each probe set, the variance of mean signal intensities was estimated, improved by an empirical Bayes method for combining variances of probes showing similar variability, and the significance of the difference between the means was evaluated with a $t$-test to obtain $p$ values. $p$ values were adjusted for multiple hypothesis testing using the Benjamini and Hochberg method to control the false discovery rate [154,155]. Raw Agilent microarray data (GLDS-113 and GLDS-370) were downloaded from NASA GeneLab. Data were analyzed using Gene Spring software (Agilent Technologies, Santa Clara, CA, USA). Background correction was performed using the 'normexp' method (with offset $=50$ ), and between array normalization was performed utilizing the quantile normalization method with a $\log 2$ transformation. Control probes and those without a RefSeq ID were removed, while probes mapping to the same RefSeq ID were collapsed by mean expression (leaving $\sim 20,700$ genes for analysis). All datasets used are outlined in Table 1 and anatomical locations of mammalian muscles are shown in Figure 1.

\subsection{Pathway Analysis}

First, differential expression analysis (DEA) was performed to reveal DEGs, the top 10 of which sorted by fold change values were used to pinpoint central players that orchestrate 
the response to spaceflight. ORA using WebGestalt [156] was then performed on DEGs to determine enriched gene ontology terms (Log2 FC $>0.32$ or $<-0.32$, FDR adjusted $p<0.05)$. A variance stabilizing transformation was applied to the count data from datasets GLDS-99 and GLDS-104, and a Gene Set Enrichment Analysis was performed with FDR threshold of $<0.1$ using Cytoscape [157]. The EnrichmentMap and Autoannotate Cytoscape plugins were used to visualize and annotate clusters of overlapping gene sets to help identify overarching enriched functional themes and aid in the interpretation of the effects of spaceflight in distinct muscle types. A comparative analysis was performed on the results from each muscle.

\section{Conclusions}

This study aimed to determine the effects of spaceflight on the transcriptome of distinct mammalian muscle types and to define shared transcriptomic signatures across a variety of model organisms. Our analyses revealed that spaceflight elicited both shared and discrete responses in representative slow and fast twitch muscle types (soleus and EDL respectively). The shared responses between these muscle types include altered expression of genes involved in GC stress responses and the circadian rhythm. These two muscle types displayed differences in transcriptomic signatures pertaining to immune function and cellular growth, with the EDL exhibiting greater degree of differential regulation of these processes based on the number of differentially expressed genes between spaceflight and ground samples. Additionally, EDL and soleus showed differences in the transcriptomic response of genes involved in ER stress mechanisms. Our findings also highlight the possible role of $P d e 2 a$ as a key molecule that may confer the atrophy resistance seen in the EDL. We also found that the muscle specific Ubiquitin E ligase Fbxo40 was downregulated across models for muscle atrophy (bedrest and spaceflight), suggesting a possible target for countermeasures development. These results were also used as a backdrop for the comparison to spaceflight responses of non-mammalian models. The molecular signature of $C$. elegans in response to spaceflight showed greater similarity to that of the EDL. Furthermore, the transcriptomic signature of the larval stage of D. melanogaster showed more similarity to the slow twitch muscle soleus. In contrast, the response of adult D. melanogaster was more akin to that of fast twitch muscle EDL. Muscles from rodent spaceflight and human bedrest studies indicate alterations in glucose homeostasis and circadian rhythm which are consistent with findings in humans that experienced spaceflight.

As expected for a highly resource intensive data collection endeavor, spaceflight omics datasets are rare and can have differences in experiment designs. One of the advantages of applying unbiased bioinformatics analyses of gene expression data is that patterns, differences, or similarities in the regulation of biological processes can be observed from a relatively small number of datasets. We have demonstrated that such an approach can be used to continue to gain insight on the shared responses across model organisms and also between ground and flight analogs for microgravity. However, we recognize limitations in this study, including the possibility that differing experiment designs across datasets such as duration of flight, relative life stage and gender and sex can impact the results obtained. In addition, several datasets yielded a relatively small number of differentially expressed genes, which can limit the ability to find shared molecular signatures across multiple datasets. As more spaceflight and analog datasets become available from the various model organisms, follow-up analyses can be conducted using the approach we have employed. We anticipate that doing so will reveal additional shared mechanisms across the model organisms of spaceflight. Although the use of invertebrate models such as D. melanogaster and C. elegans show promise in anticipating select spaceflight responses of specific muscles, our findings also confirm the marked differences in molecular signatures across these model organisms when dissections are not possible. Hence, the use of rodents to extrapolate human responses to spaceflight continue to have major advantages from a physiology perspective versus classic non-mammalian genetic model systems such as D. melanogaster and C. elegans. However, our findings raise the possibility of using 
invertebrate models as a first step toward conducting precision animal research in future deep space missions.

Supplementary Materials: The following are available online at https:/ /www.mdpi.com/article/10 $.3390 / \mathrm{ijms} 22179470 / \mathrm{s} 1$.

Author Contributions: Conceptualization, C.G.T.T.; data analysis, T.C., C.G.T.T., J.J.B., W.A.d.S., R.H., A.M.P., E.G.O. and R.G.; interpretation of results, T.C., C.G.T.T., H.C., J.J.B., T.M., S.V.C., G.H., N.J.S. and R.H.; writing-original draft preparation, T.C., H.C. and C.G.T.T., resources: S.V.C., G.H., S.S.R. and N.J.S. All authors are members of the GeneLab Animal Analysis Working Group (AWG), a working group that meets regularly to discuss and share analysis of the various GeneLab datasets, interpret the results of these analysis in the context of space biology, and guide the computational workflow. All authors have reached consensus regarding the computational workflow used in this study and reviewed and edited the manuscript. All authors have read and agreed to the published version of the manuscript.

Funding: T.C. was supported by the NI Department for the Economy (DfE) Research Studentship. H.C. is supported by the Horizon Centre for Doctoral Training at the University of Nottingham (UKRI grant no. EP/S023305/1). R.H. is supported by the Spanish Plan Estatal de Investigación Científica y Desarrollo Tecnológico Grant RTI2018-099309-B-I00. S.S.R. is supported by the NASA Ames Space Biology Program.

Institutional Review Board Statement: Not applicable.

Informed Consent Statement: Not applicable.

Data Availability Statement: The transcriptomic datasets that support the findings of this study are publicly available in NASA Genelab and NCBI Gene Expression Omnibus. All other data associated with this study are found in the main manuscript and supplementary section.

Acknowledgments: GeneLab data are courtesy of the NASA GeneLab Data Repository [158]. We thank Samrawit Gebre, Matthew Geniza, Homer Fogle, Daniel Berrios, and Amanda Saravia-Butler for guidance and advice on the use of data in the GeneLab database.

Conflicts of Interest: The authors declare no conflict of interest.

\section{References}

1. Afshinnekoo, E.; Scott, R.T.; MacKay, M.J.; Pariset, E.; Cekanaviciute, E.; Barker, R.; Gilroy, S.; Hassane, D.; Smith, S.M.; Zwart, S.R. Fundamental biological features of spaceflight: Advancing the field to enable Deep-space exploration. Cell 2020, 183, 1162-1184. [CrossRef] [PubMed]

2. Gulimova, V.; Proshchina, A.; Kharlamova, A.; Krivova, Y.; Barabanov, V.; Berdiev, R.; Asadchikov, V.; Buzmakov, A.; Zolotov, D.; Saveliev, S. Reptiles in space Missions: Results and perspectives. Int. J. Mol. Sci. 2019, 20, 3019. [CrossRef] [PubMed]

3. Leandro, L.; Szewczyk, N.; Benguria, A.; Herranz, R.; Laván, D.; Medina, F.J.; Gasset, G.; van Loon, J.; Conley, C.; Marco, R. Comparative analysis of Drosophila melanogaster and Caenorhabditis elegans gene expression experiments in the European Soyuz flights to the International Space Station. Adv. Space Res. 2007, 40, 506-512. [CrossRef] [PubMed]

4. Lang, T.; Van Loon, J.J; Bloomfield, S.; Vico, L.; Chopard, A.; Rittweger, J.; Kyparos, A.; Blottner, D.; Vuori, I.; Gerzer, R. Towards human exploration of space: The THESEUS review series on muscle and bone research priorities. NPJ Micrograv. 2017, 3, 1-10. [CrossRef]

5. Pollard, A.K.; Gaffney, C.J.; Deane, C.S.; Balsamo, M.; Cooke, M.; Ellwood, R.A.; Hewitt, J.E.; Mierzwa, B.E.; Mariani, A.; Vanapalli, S.A. Molecular muscle experiment: Hardware and operational lessons for future astrobiology space experiments. Astrobiology 2020, 20, 935-943. [CrossRef]

6. Winnard, A.; Scott, J.; Waters, N.; Vance, M.; Caplan, N. Effect of time on human muscle outcomes during simulated microgravity exposure without countermeasures-Systematic review. Front. Physiol. 2019, 10, 1046. [CrossRef]

7. Ray, S.; Gebre, S.; Fogle, H.; Berrios, D.C.; Tran, P.B.; Galazka, J.M.; Costes, S.V. GeneLab: Omics database for spaceflight experiments. Bioinformatics 2018, 35, 1753-1759. [CrossRef]

8. Berrios, D.C.; Galazka, J.; Grigorev, K.; Gebre, S.; Costes, S.V. NASA GeneLab: Interfaces for the exploration of space omics data. Nucleic Acids Res. 2021, 49, D1515-D1522. [CrossRef]

9. Edgar, R.; Domrachev, M.; Lash, A.E. Gene Expression Omnibus: NCBI gene expression and hybridization array data repository. Nucleic Acids Res. 2002, 30, 207-210. [CrossRef]

10. Severinsen, M.C.K.; Pedersen, B.K. Muscle-Organ crosstalk: The emerging roles of myokines. Endocr. Rev. 2020, 41, 594-609. [CrossRef] 
11. Mukund, K.; Subramaniam, S. Skeletal muscle: A review of molecular structure and function, in health and disease. Wiley Interdiscip. Rev. Syst. Biol. Med. 2020, 12, e1462. [CrossRef]

12. Musacchia, X.; Steffen, J.; Fell, R.; Dombrowski, M. Skeletal muscle response to spaceflight, whole body suspension, and recovery in rats. J. Appl. Physiol. 1990, 69, 2248-2253. [CrossRef]

13. Adams, G.R.; Caiozzo, V.J.; Baldwin, K.M. Skeletal muscle unweighting: Spaceflight and ground-based models. J. Appl. Physiol. 2003, 95, 2185-2201. [CrossRef]

14. Fitts, R.H.; Desplanches, D.; Romatowski, J.G.; Widrick, J.J. Spaceflight effects on single skeletal muscle fiber function in the rhesus monkey. Am. J. Physiol. Regul. Integr. Comp. Physiol. 2000, 279, R1546-R1557. [CrossRef]

15. Edgerton, V.; Zhou, M.; Ohira, Y.; Klitgaard, H.; Jiang, B.; Bell, G.; Harris, B.; Saltin, B.; Gollnick, P.; Roy, R. Human fiber size and enzymatic properties after 5 and 11 days of spaceflight. J. Appl. Physiol. 1995, 78, 1733-1739. [CrossRef]

16. Qaisar, R.; Karim, A.; Elmoselhi, A.B. Muscle unloading: A comparison between spaceflight and ground-based models. Acta Physiol. 2020, 228, e13431. [CrossRef]

17. Choi, S.Y.; Saravia-Butler, A.; Shirazi-Fard, Y.; Leveson-Gower, D.; Stodieck, L.S.; Cadena, S.M.; Beegle, J.; Solis, S.; Ronca, A.; Globus, R.K. Validation of a new rodent experimental system to investigate consequences of long duration space habitation. Sci. Rep. 2020, 10, 2336. [CrossRef]

18. Lee, S.-J.; Lehar, A.; Meir, J.U.; Koch, C.; Morgan, A.; Warren, L.E.; Rydzik, R.; Youngstrom, D.W.; Chandok, H.; George, J. Targeting myostatin/activin A protects against skeletal muscle and bone loss during spaceflight. Proc. Natl. Acad. Sci. USA 2020, 117, 23942-23951. [CrossRef]

19. Harrison, B.C.; Allen, D.L.; Girten, B.; Stodieck, L.S.; Kostenuik, P.J.; Bateman, T.A.; Morony, S.; Lacey, D.; Leinwand, L.A. Skeletal muscle adaptations to microgravity exposure in the mouse. J. Appl. Physiol. 2003, 95, 2462-2470. [CrossRef]

20. Cadena, S.M.; Zhang, Y.; Fang, J.; Brachat, S.; Kuss, P.; Giorgetti, E.; Stodieck, L.S.; Kneissel, M.; Glass, D.J. Skeletal muscle in MuRF1 null mice is not spared in low-gravity conditions, indicating atrophy proceeds by unique mechanisms in space. Sci. Rep. 2019, 9, 9397. [CrossRef]

21. Beheshti, A.; Ray, S.; Fogle, H.; Berrios, D.; Costes, S.V. A microRNA signature and TGF- $\beta 1$ response were identified as the key master regulators for spaceflight response. PLoS ONE 2018, 13, e0199621. [CrossRef] [PubMed]

22. Fujita, S.I.; Rutter, L.; Ong, Q.; Muratani, M. Integrated RNA-seq Analysis Indicates Asynchrony in Clock Genes between Tissues under Spaceflight. Life 2020, 10, 196. [CrossRef] [PubMed]

23. Augusto, V.; Padovani, C.R.; Campos, G.E.R. Skeletal muscle fiber types in C57BL6J mice. J. Morphol. Sci. 2017, $21,2$.

24. Alibegovic, A.C.; Sonne, M.P.; Højbjerre, L.; Bork-Jensen, J.; Jacobsen, S.; Nilsson, E.; Faerch, K.; Hiscock, N.; Mortensen, B.; Friedrichsen, M.; et al. Insulin resistance induced by physical inactivity is associated with multiple transcriptional changes in skeletal muscle in young men. Am. J. Physiol. Endocrinol. Metab. 2010, 299, E752-E763. [CrossRef]

25. Allen, D.L.; Bandstra, E.R.; Harrison, B.C.; Thorng, S.; Stodieck, L.S.; Kostenuik, P.J.; Morony, S.; Lacey, D.L.; Hammond, T.G.; Leinwand, L.L. Effects of spaceflight on murine skeletal muscle gene expression. J. Appl. Physiol. 2009, 106, 582-595. [CrossRef]

26. Rutter, L.; Barker, R.; Bezdan, D.; Cope, H.; Costes, S.V.; Degoricija, L.; Fisch, K.M.; Gabitto, M.I.; Gebre, S.; Giacomello, S. A New Era for Space Life Science: International Standards for Space Omics Processing. Patterns 2020, 1, 100148. [CrossRef]

27. Herranz, R.; Díaz-Castillo, C.; Nguyen, T.P.; Lovato, T.L.; Cripps, R.M.; Marco, R. Expression patterns of the whole troponin C gene repertoire during Drosophila development. Gene Expr. Patterns 2004, 4, 183-190. [CrossRef]

28. Higashibata, A.; Szewczyk, N.J.; Conley, C.A.; Imamizo-Sato, M.; Higashitani, A.; Ishioka, N. Decreased expression of myogenic transcription factors and myosin heavy chains in Caenorhabditis elegans muscles developed during spaceflight. J. Exp. Biol. 2006, 209, 3209-3218. [CrossRef]

29. Higashibata, A.; Hashizume, T.; Nemoto, K.; Higashitani, N.; Etheridge, T.; Mori, C.; Harada, S.; Sugimoto, T.; Szewczyk, N.J.; Baba, S.A. Microgravity elicits reproducible alterations in cytoskeletal and metabolic gene and protein expression in space-flown Caenorhabditis elegans. NPJ Micrograv. 2016, 2, 15022. [CrossRef]

30. Herranz, R.; Benguría, A.; Laván, D.A.; López-Vidriero, I.; Gasset, G.; Javier Medina, F.; van Loon, J.J.; Marco, R. Spaceflightrelated suboptimal conditions can accentuate the altered gravity response of Drosophila transcriptome. Mol. Ecol. 2010, 19, 4255-4264. [CrossRef]

31. Adenle, A.; Johnsen, B.; Szewczyk, N. Review of the results from the International C. elegans first experiment (ICE-FIRST). Adv. Space Res. 2009, 44, 210-216. [CrossRef]

32. Fire, A.; Xu, S.; Montgomery, M.K.; Kostas, S.A.; Driver, S.E.; Mello, C.C. Potent and specific genetic interference by doublestranded RNA in Caenorhabditis elegans. Nature 1998, 391, 806-811. [CrossRef]

33. The, C. Elegans Sequencing Consortium. Genome sequence of the nematode C. elegans: A platform for investigating biology. Science 1998, 282, 2012-2018.

34. Kenyon, C.; Chang, J.; Gensch, E.; Rudner, A.; Tabtiang, R. A C. elegans mutant that lives twice as long as wild type. Nature 1993, 366, 461-464. [CrossRef]

35. Clancy, D.J.; Gems, D.; Harshman, L.G.; Oldham, S.; Stocker, H.; Hafen, E.; Leevers, S.J.; Partridge, L. Extension of life-span by loss of CHICO, a Drosophila insulin receptor substrate protein. Science 2001, 292, 104-106. [CrossRef]

36. Tatar, M.; Kopelman, A.; Epstein, D.; Tu, M.P.; Yin, C.M.; Garofalo, R.S. A mutant Drosophila insulin receptor homolog that extends life-span and impairs neuroendocrine function. Science 2001, 292, 107-110. [CrossRef] 
37. Kappeler, L.; De Magalhaes Filho, C.; Dupont, J.; Leneuve, P.; Cervera, P.; Périn, L.; Loudes, C.; Blaise, A.; Klein, R.; Epelbaum, J.; et al. Brain IGF-1 receptors control mammalian growth and lifespan through a neuroendocrine mechanism. PLoS Biol. 2008, 6, e254. [CrossRef]

38. Suh, Y.; Atzmon, G.; Cho, M.-O.; Hwang, D.; Liu, B.; Leahy, D.J.; Barzilai, N.; Cohen, P. Functionally significant insulin-like growth factor I receptor mutations in centenarians. Proc. Natl. Acad. Sci. USA 2008, 105, 3438-3442. [CrossRef]

39. Gene Lab. Open Science for Life in Space. Drosophila melanogaster Gene Expression Changes after Spaceflight. Version 5. 2011. Available online: https:/ / genelab-data.ndc.nasa.gov/genelab/accession/GLDS-3/ (accessed on 21 August 2021).

40. Gene Lab. Open Science for Life in Space. Rodent Research-1 (RR1) NASA Validation Flight: Mouse Extensor Digitorum Longus Muscle Transcriptomic and Epigenomic Data. Version 4. 2017. Available online: https://genelab-data.ndc.nasa.gov/genelab/ accession/GLDS-99/ (accessed on 21 August 2021).

41. Gene Lab. Open Science for Life in Space. Rodent Research-1 (RR1) NASA Validation Flight: Mouse Quadriceps Muscle Transcriptomic, Proteomic, and Epigenomic Data. Version 4. 2017. Available online: https://genelab-data.ndc.nasa.gov/genelab/ accession/GLDS-103/ (accessed on 21 August 2021).

42. Gene Lab. Open Science for Life in Space. Rodent Research-1 (RR1) NASA Validation Flight: Mouse Soleus Muscle Transcriptomic and Epigenomic Data. Version 4. 2017. Available online: https://genelab-data.ndc.nasa.gov/genelab/accession/GLDS-104/ (accessed on 21 August 2021).

43. Gene Lab. Open Science for Life in Space. Expression Data from International C. elegans Experiment 1st (ICE-FIRST). Version 1. 2016. Available online: https://genelab-data.ndc.nasa.gov/genelab/accession/GLDS-113/ (accessed on 21 August 2021).

44. Bai, Z.; Chai, X.-R.; Yoon, M.J.; Kim, H.-J.; Lo, K.A.; Zhang, Z.-C.; Xu, D.; Siang, D.T.C.; Walet, A.C.E.; Xu, S.-H.; et al. Dynamic transcriptome changes during adipose tissue energy expenditure reveal critical roles for long noncoding RNA regulators. PLoS Biol. 2017, 15, e2002176. [CrossRef]

45. Wang, C.; Zhang, B.; Ratliff, A.C.; Arlington, J.; Chen, J.; Xiong, Y.; Yue, F.; Nie, Y.; Hu, K.; Jin, W. Methyltransferase-like 21e inhibits 26S proteasome activity to facilitate hypertrophy of type IIb myofibers. FASEB J. 2019, 33, 9672-9684. [CrossRef]

46. Da Silveira, W.A.; Fazelinia, H.; Rosenthal, S.B.; Laiakis, E.C.; Kim, M.S.; Meydan, C.; Kidane, Y.; Rathi, K.S.; Smith, S.M.; Stear, B. Comprehensive multi-omics analysis reveals mitochondrial stress as a central biological hub for spaceflight impact. Cell 2020, 183, 1185-1201.e1120. [CrossRef] [PubMed]

47. Beheshti, A.; Chakravarty, K.; Fogle, H.; Fazelinia, H.; da Silveira, W.A.; Boyko, V.; Polo, S.-H.L.; Saravia-Butler, A.M.; Hardiman, G.; Taylor, D. Multi-Omics analysis of multiple missions to space reveal a theme of lipid dysregulation in mouse liver. Sci. Rep. 2019, 9, 19195. [CrossRef] [PubMed]

48. Overbey, E.G.; da Silveira, W.A.; Stanbouly, S.; Nishiyama, N.C.; Roque-Torres, G.D.; Pecaut, M.J.; Zawieja, D.C.; Wang, C.; Willey, J.S.; Delp, M.D. Spaceflight influences gene expression, photoreceptor integrity, and oxidative stress-related damage in the murine retina. Sci. Rep. 2019, 9, 13304. [CrossRef] [PubMed]

49. Yamaguchi, S.; Mitsui, S.; Yan, L.; Yagita, K.; Miyake, S.; Okamura, H. Role of DBP in the circadian oscillatory mechanism. Mol. Cell. Biol. 2000, 20, 4773-4781. [CrossRef] [PubMed]

50. Stein, T.; Wade, C. Metabolic consequences of muscle disuse atrophy. J. Nutr. 2005, 135, 1824S-1828S. [CrossRef]

51. Kang, Y.; Hengbo, S.; Jun, L.; Jun, L.; Wangsheng, Z.; Huibin, T.; Huaiping, S. PPARG modulated lipid accumulation in dairy GMEC via regulation of ADRP gene. J. Cell. Biochem. 2015, 116, 192-201. [CrossRef]

52. Schoonjans, K.; Gelman, L.; Haby, C.; Briggs, M.; Auwerx, J. Induction of LPL gene expression by sterols is mediated by a sterol regulatory element and is independent of the presence of multiple E boxes. J. Mol. Biol. 2000, 304, 323-334. [CrossRef]

53. Paz-Filho, G.; Ayala, A.; Esposito, K.; Erol, H.; Delibasi, T.; Barry, E.; Wong, M.-L.; Licinio, J. Effects of leptin on lipid metabolism. Horm. Metab. Res. 2008, 40, 572-574. [CrossRef]

54. Jonscher, K.R.; Alfonso-Garcia, A.; Suhalim, J.L.; Orlicky, D.J.; Potma, E.O.; Ferguson, V.L.; Bouxsein, M.L.; Bateman, T.A.; Stodieck, L.S.; Levi, M. Spaceflight activates lipotoxic pathways in mouse liver. PLoS ONE 2016, 11, e0152877.

55. Annayev, Y.; Adar, S.; Chiou, Y.Y.; Lieb, J.D.; Sancar, A.; Ye, R. Gene model 129 (Gm129) encodes a novel transcriptional repressor that modulates circadian gene expression. J. Biol. Chem. 2014, 289, 5013-5024. [CrossRef]

56. Sandonà, D.; Desaphy, J.-F.; Camerino, G.M.; Bianchini, E.; Ciciliot, S.; Danieli-Betto, D.; Dobrowolny, G.; Furlan, S.; Germinario, E.; Goto, K. Adaptation of mouse skeletal muscle to long-term microgravity in the MDS mission. PLoS ONE 2012, 7, e33232. [CrossRef]

57. Available online: https://useast.ensembl.org/index.html (accessed on 21 August 2021).

58. Jiang, L.; Yan, Q.; Fang, S.; Liu, M.; Li, Y.; Yuan, Y.F.; Li, Y.; Zhu, Y.; Qi, J.; Yang, X. Calcium-binding protein 39 promotes hepatocellular carcinoma growth and metastasis by activating extracellular signal-regulated kinase signaling pathway. Hepatology 2017, 66, 1529-1545. [CrossRef]

59. Krokan, H.E.; Otterlei, M.; Nilsen, H.; Kavli, B.; Skorpen, F.; Andersen, S.; Skjelbred, C.; Akbari, M.; Aas, P.A.; Slupphaug, G. Properties and functions of human uracil-DNA glycosylase from the UNG gene. Prog. Nucleic Acid Res. Mol. Biol. 2001, 68, 365-386. [CrossRef]

60. Vitorino, M.; Correia, E.; Serralheiro, A.-R.; De-Jesus, A.-C.; Inácio, J.M.; Belo, J.A. Expression pattern of zcchc24 during early Xenopus development. Int. J. Dev. Biol. 2014, 58, 45-50. [CrossRef]

61. Amillet, J.-M.; Ferbus, D.; Real, F.X.; Antony, C.; Muleris, M.; Gress, T.M.; Goubin, G. Characterization of human Rab20 overexpressed in exocrine pancreatic carcinoma. Hum. Pathol. 2006, 37, 256-263. [CrossRef] 
62. Lu, G.; Sun, H.; She, P.; Youn, J.-Y.; Warburton, S.; Ping, P.; Vondriska, T.M.; Cai, H.; Lynch, C.J.; Wang, Y. Protein phosphatase 2Cm is a critical regulator of branched-chain amino acid catabolism in mice and cultured cells. J. Clin. Investig. 2009, 119, 1678-1687. [CrossRef]

63. Potts, P.R.; Porteus, M.H.; Yu, H. Human SMC5/6 complex promotes sister chromatid homologous recombination by recruiting the SMC1/3 cohesin complex to double-strand breaks. EMBO J. 2006, 25, 3377-3388. [CrossRef]

64. Safdie, G.; Liewald, J.F.; Kagan, S.; Battat, E.; Gottschalk, A.; Treinin, M. RIC-3 phosphorylation enables dual regulation of excitation and inhibition of Caenorhabditis elegans muscle. Mol. Biol. Cell 2016, 27, 2994-3003. [CrossRef]

65. Kaeser-Woo, Y.J.; Younts, T.J.; Yang, X.; Zhou, P.; Wu, D.; Castillo, P.E.; Südhof, T.C. Synaptotagmin-12 phosphorylation by cAMP-dependent protein kinase is essential for hippocampal mossy fiber LTP. J. Neurosci. 2013, 33, 9769-9780. [CrossRef]

66. Ciranna, L.; Catania, M.V. 5- $\mathrm{HT}_{7}$ receptors as modulators of neuronal excitability, synaptic transmission and plasticity: Physiological role and possible implications in autism spectrum disorders. Front. Cell Neurosci. 2014, 8, 250. [CrossRef]

67. Röhrborn, D.; Wronkowitz, N.; Eckel, J. DPP4 in diabetes. Front. Immunol. 2015, 6, 386. [CrossRef]

68. Wing, M.R.; Bourdon, D.M.; Harden, T.K. PLC- $\varepsilon$ : A shared effector protein in Ras-, Rho-, and G $\alpha \beta \gamma$-mediated signaling. Mol. Interv. 2003, 3, 273-280. [CrossRef]

69. Ma, L.; Ma, J.; Xu, K. Effect of spaceflight on the circadian rhythm, lifespan and gene expression of Drosophila melanogaster. PLoS ONE 2015, 10, e0121600. [CrossRef]

70. Cheng, H.-P.; Liu, Q.; Li, Y.; Li, X.-D.; Zhu, C.-Y. The inhibitory effect of PDIA6 downregulation on bladder cancer cell proliferation and invasion. Oncol. Res. 2017, 25, 587-593. [CrossRef]

71. Gao, H.; Sun, B.; Fu, H.; Chi, X.; Wang, F.; Qi, X.; Hu, J.; Shao, S. PDIA6 promotes the proliferation of HeLa cells through activating the Wnt/ $\beta$-catenin signaling pathway. Oncotarget 2016, 7, 53289. [CrossRef]

72. Chen, D.; Li, F.; Yang, Q.; Tian, M.; Zhang, Z.; Zhang, Q.; Chen, Y.; Guan, M.-X. The defective expression of gtpbp3 related to tRNA modification alters the mitochondrial function and development of zebrafish. Int. J. Biochem. Cell Biol. 2016, 77, 1-9. [CrossRef]

73. Zhang, J.; Qu, C.; Li, T.; Cui, W.; Wang, X.; Du, J. Phagocytosis mediated by scavenger receptor class BI promotes macrophage transition during skeletal muscle regeneration. J. Biol. Chem. 2019, 294, 15672-15685. [CrossRef]

74. Seko, D.; Ogawa, S.; Li, T.S.; Taimura, A.; Ono, Y. $\mu$-Crystallin controls muscle function through thyroid hormone action. FASEB J. 2016, 30, 1733-1740. [CrossRef]

75. Tariq, N.; Basharat, Z.; Butt, S.; Baig, D.N. Distribution analysis of profilin isoforms at transcript resolution with mRNA-seq and secondary structure in various organs of Rattus norvegicus. Gene 2016, 589, 49-55. [CrossRef]

76. Wang, B.; Zhou, Q.; Bi, Y.; Zhou, W.; Zeng, Q.; Liu, Z.; Liu, X.; Zhan, Z. Phosphatase PPM1L prevents excessive inflammatory responses and cardiac dysfunction after myocardial infarction by inhibiting IKK $\beta$ activation. J. Immunol. 2019, 203, 1338-1347. [CrossRef]

77. Clarke, B.A.; Drujan, D.; Willis, M.S.; Murphy, L.O.; Corpina, R.A.; Burova, E.; Rakhilin, S.V.; Stitt, T.N.; Patterson, C.; Latres, E. The E3 Ligase MuRF1 degrades myosin heavy chain protein in dexamethasone-treated skeletal muscle. Cell Metab. 2007, 6, 376-385. [CrossRef] [PubMed]

78. Adhikari, A.; Mainali, P.; Davie, J.K. JARID2 and the PRC2 complex regulate the cell cycle in skeletal muscle. J. Biol. Chem. 2019, 294, 19451-19464. [CrossRef]

79. Uretmen Kagiali, Z.C.; Sanal, E.; Karayel, Ö.; Polat, A.N.; Saatci, Ö.; Ersan, P.G.; Trappe, K.; Renard, B.Y.; Önder, T.T.; Tuncbag, N.; et al. Systems-Level analysis reveals multiple modulators of epithelial-mesenchymal transition and identifies DNAJB4 and CD81 as novel metastasis inducers in breast cancer. Mol. Cell Proteom. 2019, 18, 1756-1771. [CrossRef] [PubMed]

80. Puntschart, A.; Wey, E.; Jostarndt, K.; Vogt, M.; Wittwer, M.; Widmer, H.; Hoppeler, H.; Billeter, R. Expression of fos and jun genes in human skeletal muscle after exercise. Am. J. Physiol. Cell Physiol. 1998, 274, C129-C137. [CrossRef] [PubMed]

81. Davis, S.R.; Cousins, R.J. Metallothionein expression in animals: A physiological perspective on function. J. Nutr. 2000, 130, 1085-1088. [CrossRef]

82. Mao, B.; Zhang, Z.; Wang, G. BTG2: A rising star of tumor suppressors. Int. J. Oncol. 2015, 46, 459-464. [CrossRef]

83. Pan, Y.-C.; Li, C.-F.; Ko, C.-Y.; Pan, M.-H.; Chen, P.-J.; Tseng, J.T.; Wu, W.-C.; Chang, W.-C.; Huang, A.-M.; Sterneck, E. CEBPD reverses RB/E2F1-mediated gene repression and participates in HMDB-induced apoptosis of cancer cells. Clin. Cancer Res. 2010, 16, 5770-5780. [CrossRef]

84. Ying, J.; Srivastava, G.; Hsieh, W.S.; Gao, Z.; Murray, P.; Liao, S.K.; Ambinder, R.; Tao, Q. The stress-responsive gene GADD45G is a functional tumor suppressor, with its response to environmental stresses frequently disrupted epigenetically in multiple tumors. Clin. Cancer Res. 2005, 11, 6442-6449. [CrossRef]

85. Löhr, K.; Möritz, C.; Contente, A.; Dobbelstein, M. p21/CDKN1A mediates negative regulation of transcription by p53. J. Biol. Chem. 2003, 278, 32507-32516. [CrossRef]

86. Tomasini, R.; Seux, M.; Nowak, J.; Bontemps, C.; Carrier, A.; Dagorn, J.-C.; Pébusque, M.-J.; Iovanna, J.L.; Dusetti, N.J. TP53INP1 is a novel p73 target gene that induces cell cycle arrest and cell death by modulating p73 transcriptional activity. Oncogene 2005, 24, 8093-8104. [CrossRef]

87. Li, Y.; Kang, H.; Chu, Y.; Jin, Y.; Zhang, L.; Yang, R.; Zhang, Z.; Zhao, S.; Zhou, L. Cidec differentially regulates lipid deposition and secretion through two tissue-specific isoforms. Gene 2018, 641, 265-271. [CrossRef]

88. Kjøbsted, R.; Chadt, A.; Jørgensen, N.O.; Kido, K.; Larsen, J.K.; de Wendt, C.; Al-Hasani, H.; Wojtaszewski, J.F.P. TBC1D4 is necessary for enhancing muscle insulin sensitivity in response to AICAR and contraction. Diabetes 2019, 68, 1756-1766. [CrossRef] 
89. McQueeney, K.E.; Salamoun, J.M.; Ahn, J.G.; Pekic, P.; Blanco, I.K.; Struckman, H.L.; Sharlow, E.R.; Wipf, P.; Lazo, J.S. A chemical genetics approach identifies PTP4A3 as a regulator of colon cancer cell adhesion. FASEB J. 2018, 32, 5661-5673. [CrossRef]

90. Ye, J.; Zhang, Y.; Xu, J.; Zhang, Q.; Zhu, D. FBXO40, a gene encoding a novel muscle-specific F-box protein, is upregulated in denervation-related muscle atrophy. Gene 2007, 404, 53-60. [CrossRef]

91. Eftestøl, E.; Alver, T.N.; Gundersen, K.; Bruusgaard, J.C. Overexpression of SMPX in adult skeletal muscle does not change skeletal muscle fiber type or size. PLoS ONE 2014, 9, e99232. [CrossRef]

92. Hawke, T.J.; Garry, D.J. Myogenic satellite cells: Physiology to molecular biology. J. Appl. Physiiol. 2001, 91, 534-551. [CrossRef]

93. Yin, H.; Price, F.; Rudnicki, M.A. Satellite cells and the muscle stem cell niche. Physiol. Rev. 2013, 93, 23-67. [CrossRef]

94. Kami, K.; Noguchi, K.; Senba, E. Localization of myogenin, c-fos, c-jun, and muscle-specific gene mRNAs in regenerating rat skeletal muscle. Cell Tissue Res. 1995, 280, 11-19. [CrossRef]

95. Buckingham, M. Skeletal muscle progenitor cells and the role of Pax genes. C. R. Biol. 2007, 330, 530-533. [CrossRef]

96. Radugina, E.A.; Almeida, E.A.C.; Blaber, E.; Poplinskaya, V.A.; Markitantova, Y.V.; Grigoryan, E.N. Exposure to microgravity for 30 days onboard Bion M1 caused muscle atrophy and impaired regeneration in murine femoral quadriceps. Life Sci. Space Res. 2018, 16, 18-25. [CrossRef]

97. Tahimic, C.G.T.; Paul, A.M.; Schreurs, A.S.; Torres, S.M.; Rubinstein, L.; Steczina, S.; Lowe, M.; Bhattacharya, S.; Alwood, J.S.; Ronca, A.E.; et al. Influence of social isolation during prolonged simulated weightlessness by hindlimb Unloading. Front. Physiol 2019, 10, 1147. [CrossRef] [PubMed]

98. Paul, A.M.; Mhatre, S.D.; Cekanaviciute, E.; Schreurs, A.S.; Tahimic, C.G.T.; Globus, R.K.; Anand, S.; Crucian, B.E.; Bhattacharya, S. Neutrophil-to-Lymphocyte ratio: A biomarker to monitor the immune status of astronauts. Front. Immunol. 2020, 11, 564950. [CrossRef] [PubMed]

99. Bigley, A.B.; Agha, N.H.; Baker, F.L.; Spielmann, G.; Kunz, H.E.; Mylabathula, P.L.; Rooney, B.V.; Laughlin, M.S.; Mehta, S.K.; Pierson, D.L.; et al. NK cell function is impaired during long-duration spaceflight. J. Appl. Physiol. 2019, 126, 842-853. [CrossRef] [PubMed]

100. Mehta, S.K.; Laudenslager, M.L.; Stowe, R.P.; Crucian, B.E.; Feiveson, A.H.; Sams, C.F.; Pierson, D.L. Latent virus reactivation in astronauts on the international space station. NPJ Micrograv. 2017, 3, 11. [CrossRef] [PubMed]

101. Frippiat, J.P.; Crucian, B.E.; de Quervain, D.J.; Grimm, D.; Montano, N.; Praun, S.; Roozendaal, B.; Schelling, G.; Thiel, M.; Ullrich, O.; et al. Towards human exploration of space: The THESEUS review series on immunology research priorities. NPJ Micrograv. 2016, 2, 16040. [CrossRef] [PubMed]

102. Crucian, B.E.; Chouker, A.; Simpson, R.J.; Mehta, S.; Marshall, G.; Smith, S.M.; Zwart, S.R.; Heer, M.; Ponomarev, S.; Whitmire, A.; et al. Immune system dysregulation during spaceflight: Potential countermeasures for deep space exploration missions. Front. Immunol. 2018, 9, 1437. [CrossRef]

103. Warren, G.L.; Hulderman, T.; Mishra, D.; Gao, X.; Millecchia, L.; O’Farrell, L.; Kuziel, W.A.; Simeonova, P.P. Chemokine receptor CCR2 involvement in skeletal muscle regeneration. FASEB J. 2005, 19, 1-23. [CrossRef]

104. Lu, H.; Huang, D.; Ransohoff, R.M.; Zhou, L. Acute skeletal muscle injury: CCL2 expression by both monocytes and injured muscle is required for repair. FASEB J. 2011, 25, 3344-3355. [CrossRef]

105. Pistilli, E.E.; Siu, P.M.; Alway, S.E. Interleukin-15 responses to aging and unloading-induced skeletal muscle atrophy. Am. J. Physiol. Cell Physiol. 2007, 292, C1298-C1304. [CrossRef]

106. Prisby, R.D.; Alwood, J.S.; Behnke, B.J.; Stabley, J.N.; McCullough, D.J.; Ghosh, P.; Globus, R.K.; Delp, M.D. Effects of hindlimb unloading and ionizing radiation on skeletal muscle resistance artery vasodilation and its relation to cancellous bone in mice. $J$. Appl. Physiol. 2016, 120, 97-106. [CrossRef]

107. Stabley, J.N.; Dominguez, J.M.; Dominguez, C.E.; Mora Solis, F.R.; Ahlgren, J.; Behnke, B.J.; Muller-Delp, J.M.; Delp, M.D. Spaceflight reduces vasoconstrictor responsiveness of skeletal muscle resistance arteries in mice. J. Appl. Physiol. 2012, 113, 1439-1445. [CrossRef]

108. Grabham, P.; Hu, B.; Sharma, P.; Geard, C. Effects of ionizing radiation on three-dimensional human vessel models: Differential effects according to radiation quality and cellular development. Radiat. Res. 2011, 175, 21-28. [CrossRef]

109. Berdeaux, R.; Stewart, R. cAMP signaling in skeletal muscle adaptation: Hypertrophy, metabolism, and regeneration. Am. J. Physiol. Endocrinol. Metab. 2012, 303, E1-E17. [CrossRef]

110. Sandri, M.; Lin, J.; Handschin, C.; Yang, W.; Arany, Z.P.; Lecker, S.H.; Goldberg, A.L.; Spiegelman, B.M. PGC-1 $\alpha$ protects skeletal muscle from atrophy by suppressing FoxO3 action and atrophy-specific gene transcription. Proc. Natl. Acad. Sci. USA 2006, 103, 16260-16265. [CrossRef]

111. Shenkman, B. From slow to fast: Hypogravity-induced remodeling of muscle fiber myosin phenotype. Acta Nat. $2016,8,4$. [CrossRef]

112. Arany, Z.; Lebrasseur, N.; Morris, C.; Smith, E.; Yang, W.; Ma, Y.; Chin, S.; Spiegelman, B.M. The transcriptional coactivator PGC-1 $\beta$ drives the formation of oxidative type IIX fibers in skeletal muscle. Cell Metab. 2007, 5, 35-46. [CrossRef]

113. Macho, L.; Kvetňanský, R.; Vigaš, M.; Németh, S.; Popova, I.; Tigranian, R.A.; Noskov, V.B.; Serova, L.; Grigoriev, I.A. Effect of space flights on plasma hormone levels in man and in experimental animal. Acta Astronaut. 1991, 23, 117-121. [CrossRef]

114. Stowe, R.P.; Pierson, D.L.; Feeback, D.L.; Barrett, A.D. Stress-induced reactivation of Epstein-Barr virus in astronauts. Neuroimmunomodulation 2000, 8, 51-58. [CrossRef]

115. Braun, T.P.; Marks, D.L. The regulation of muscle mass by endogenous glucocorticoids. Front. Physiol. 2015, 6, 12. [CrossRef] 
116. Ruginsk, S.G.; Uchoa, E.T.; Leite, C.M.; Martins, C.S.; de Araujo, L.D.; de Castro, M.; Elias, L.L.K.; Rodrigues, J.A. GlucocorticoidMediated regulation of circadian rhythms: Interface with energy homeostasis and reproduction. In Corticosteroids; IntechOpen: London, UK, 2018; Volume 25.

117. Cheon, S.; Park, N.; Cho, S.; Kim, K. Glucocorticoid-mediated Period2 induction delays the phase of circadian rhythm. Nucleic Acids Res. 2013, 41, 6161-6174. [CrossRef]

118. Monk, T.H.; Buysse, D.J.; Billy, B.D.; Kennedy, K.S.; Willrich, L.M. Sleep and circadian rhythms in four orbiting astronauts. J. Biol. Rhythm. 1998, 13, 188-201. [CrossRef]

119. Kondratov, R.V.; Kondratova, A.A.; Gorbacheva, V.Y.; Vykhovanets, O.V.; Antoch, M.P. Early aging and age-related pathologies in mice deficient in BMAL1, the core componentof the circadian clock. Genes Dev. 2006, 20, 1868-1873. [CrossRef]

120. Moraitis, A.G.; Block, T.; Nguyen, D.; Belanoff, J.K. The role of glucocorticoid receptors in metabolic syndrome and psychiatric illness. J. Steroid Biochem. Mol. Biol. 2017, 165, 114-120. [CrossRef] [PubMed]

121. Maury, E.; Ramsey, K.M.; Bass, J. Circadian rhythms and metabolic syndrome: From experimental genetics to human disease. Circ. Res. 2010, 106, 447-462. [CrossRef]

122. Stenvers, D.J.; Scheer, F.A.J.L.; Schrauwen, P.; la Fleur, S.E.; Kalsbeek, A. Circadian clocks and insulin resistance. Nat. Rev. Endocrinol. 2019, 15, 75-89. [CrossRef] [PubMed]

123. Czeisler, C.A.; Chiasera, A.J.; Duffy, J.F. Research on sleep, circadian rhythms and aging: Applications to manned spaceflight. Exp. Gerontol. 1991, 26, 217-232. [CrossRef]

124. Cole, J.L. Steroid-Induced sleep disturbance and delirium: A focused review for critically ill patients. Fed. Pract. 2020, 37, 260-267. [PubMed]

125. Coutinho, A.E.; Chapman, K.E. The anti-inflammatory and immunosuppressive effects of glucocorticoids, recent developments and mechanistic insights. Mol. Cell Endocrinol. 2011, 335, 2-13. [CrossRef]

126. Scheiermann, C.; Kunisaki, Y.; Frenette, P.S. Circadian control of the immune system. Nat. Rev. Immunol. 2013, 13, 190-198. [CrossRef]

127. James, E.R. The etiology of steroid cataract. J. Ocul. Pharmacol. Ther. 2007, 23, 403-420. [CrossRef]

128. Desai, B.S.; Chadha, A.; Cook, B. The stum gene is essential for mechanical sensing in proprioceptive neurons. Science 2014, 343, 1256-1259. [CrossRef]

129. Akay, T.; Tourtellotte, W.G.; Arber, S.; Jessell, T.M. Degradation of mouse locomotor pattern in the absence of proprioceptive sensory feedback. Proc. Natl. Acad. Sci. USA 2014, 111, 16877-16882. [CrossRef]

130. Ridley, A.; Hall, A. Signal transduction pathways regulating Rho-mediated stress fibre formation: Requirement for a tyrosine kinase. EMBO J. 1994, 13, 2600-2610. [CrossRef]

131. Martino, F.; Perestrelo, A.R.; Vinarský, V.; Pagliari, S.; Forte, G. Cellular mechanotransduction: From tension to function. Front. Physiol. 2018, 9, 824. [CrossRef]

132. Platzer, K.; Lemke, J.R. GRIN1-related neurodevelopmental disorder. In GeneReviews ${ }^{\circledR}$; University of Washington: Seattle, WA, USA, 2019; Available online: https:/ / europepmc.org/article/NBK/nbk542807 (accessed on 21 August 2021).

133. Lai, C.H.; Chou, C.Y.; Ch'ang, L.Y.; Liu, C.S.; LN, W. Identification of novel human genes evolutionarily conserved in Caenorhabditis elegans by comparative proteomics. Genome Res. 2000, 10, 703-713. [CrossRef]

134. Pukkila-Worley, R.; Ausubel, F.M. Immune defense mechanisms in the Caenorhabditis elegans intestinal epithelium. Curr. Opin. Immunol. 2012, 24, 3-9. [CrossRef]

135. Mateos, J.; Herranz, R.; Domingo, A.; Sparrow, J.; Marco, R. The structural role of high molecular weight tropomyosins in dipteran indirect flight muscle and the effect of phosphorylation. J. Muscle Res. Cell Motil. 2006, 27, 189-201. [CrossRef]

136. Ramani, V.C.; Haun, R.S. The extracellular matrix protein fibronectin is a substrate for kallikrein 7. Biochem. Biophys. Res. Commun. 2008, 369, 1169-1173. [CrossRef]

137. Walker, C.; Mojares, E.; del Río Hernández, A. Role of extracellular matrix in development and cancer progression. Int. J. Mol. Sci. 2018, 19, 3028. [CrossRef]

138. Ingber, D. How cells (might) sense microgravity. FASEB J. 1999, 13, S3-S15. [CrossRef]

139. Zhang, L.; Chen, Z.; Wang, Y.; Tweardy, D.J.; Mitch, W.E. Stat3 activation induces insulin resistance via a muscle-specific E3 ubiquitin ligase Fbxo40. Am. J. Physiol. Endocrinol. Metab. 2020, 318, E625-E635. [CrossRef] [PubMed]

140. Hughson, R.L.; Robertson, A.D.; Arbeille, P.; Shoemaker, J.K.; Rush, J.W.; Fraser, K.S.; Greaves, D.K. Increased postflight carotid artery stiffness and inflight insulin resistance resulting from 6-mo spaceflight in male and female astronauts. Am. J. Physiol. Heart Circ. Physiol. 2016, 310, H628-H638. [CrossRef] [PubMed]

141. Rullman, E.; Mekjavic, I.B.; Fischer, H.; Eiken, O. PlanHab (Planetary Habitat Simulation): The combined and separate effects of 21 days bed rest and hypoxic confinement on human skeletal muscle miRNA expression. Physiol. Rep. 2016, 4, e12753. [CrossRef] [PubMed]

142. Chopard, A.; Lecunff, M.; Danger, R.; Lamirault, G.; Bihouee, A.; Teusan, R.; Jasmin, B.J.; Marini, J.F.; Leger, J.J. Large-scale mRNA analysis of female skeletal muscles during 60 days of bed rest with and without exercise or dietary protein supplementation as countermeasures. Physiol. Genom. 2009, 38, 291-302. [CrossRef]

143. FastQC: A Quality Control Tool for High Throughput Sequence Data. Version 0.118. Available online: https://www. bioinformatics.babraham.ac.uk/projects/fastqc/ (accessed on 21 August 2021). 
144. Ewels, P.; Magnusson, M.; Lundin, S.; Käller, M. MultiQC: Summarize analysis results for multiple tools and samples in a single report. Bioinformatics 2016, 32, 3047-3048. [CrossRef]

145. Dobin, A.; Davis, C.A.; Schlesinger, F.; Drenkow, J.; Zaleski, C.; Jha, S.; Batut, P.; Chaisson, M.; Gingeras, T.R. STAR: Ultrafast universal RNA-seq aligner. Bioinformatics 2012, 29, 15-21. [CrossRef]

146. Li, B.; Dewey, C.N. RSEM: Accurate transcript quantification from RNA-Seq data with or without a reference genome. $B M C$ Bioinform. 2011, 12, 323. [CrossRef]

147. Ihaka, R.; Gentleman, R. R: A language for data analysis and graphics. J. Comput. Graph. Stat. 1996, 5, $299-314$.

148. Soneson, C.; Love, M.I.; Robinson, M.D. Differential analyses for RNA-seq: Transcript-level estimates improve gene-level inferences. F1000 Res. 2015, 4, 1521. [CrossRef]

149. Hu, Y.; Huang, K.; An, Q.; Du, G.; Hu, G.; Xue, J.; Zhu, X.; Wang, C.-Y.; Xue, Z.; Fan, G. Simultaneous profiling of transcriptome and DNA methylome from a single cell. Genome Biol. 2016, 17, 88. [CrossRef]

150. STRINGdb Package. Available online: https://www.bioconductor.org/packages/release/bioc/html/STRINGdb.html (accessed on 21 August 2021).

151. Mi, H.; Guo, N.; Kejariwal, A.; Thomas, P.D. PANTHER version 6: Protein sequence and function evolution data with expanded representation of biological pathways. Nucleic Acids Res. 2007, 35, D247-D252. [CrossRef]

152. Genome Wide Annotation for Human. R Package Version 3.2.3.2019. Available online: https://bioconductor.riken.jp/packages/ 3.3/data/annotation/html/org.Hs.eg.db.html (accessed on 21 August 2021).

153. Love, M.I.; Huber, W.; Anders, S. Moderated estimation of fold change and dispersion for RNA-seq data with DESeq2. Genome Biol. 2014, 15, 550. [CrossRef]

154. Jonathan, D.; Rubin, D.M. GeneLab-Microarray. Available online: https://github.com/jdrubin91/GeneLab-Microarray (accessed on 21 August 2021).

155. Benjamini, Y.; Hochberg, Y. Controlling the false discovery rate: A practical and powerful approach to multiple testing. J. R. Stat. Soc. Ser. B (Methodol.) 1995, 57, 289-300. [CrossRef]

156. Liao, Y.; Wang, J.; Jaehnig, E.J.; Shi, Z.; Zhang, B. WebGestalt 2019: Gene set analysis toolkit with revamped UIs and APIs. Nucleic Acids Res. 2019, 47, W199-W205. [CrossRef]

157. Smoot, M.E.; Ono, K.; Ruscheinski, J.; Wang, P.-L.; Ideker, T. Cytoscape 2.8: New features for data integration and network visualization. Bioinformatics 2011, 27, 431-432. [CrossRef]

158. NASA GeneLab. Available online: https://genelab-data.ndc.nasa.gov /genelab / projects?page=1\&paginate_by=25 (accessed on 21 August 2021). 